\title{
Un castrum des environs de l'An Mil en Languedoc central : le Rocher des Vierges à Saint-Saturnin (Hérault)
}

In: Archéologie du Midi médiéval. Tome 6, 1988. pp. 101-122.

\section{Résumé}

Depuis 1986, est entreprise en parallèle avec la fouille programmée de la Cisterne à Cabrières (Hérault), une série de démarches complémentaires sur d'autres sites des campagnes de la moyenne vallée de l'Hérault. Sondages prospectifs, prospections systématiques au sol et aériennes permettent d'appréhender plus justement les structures du peuplement de cette micro-région. L'étude de cas établie pour le Rocher des Vierges à Saint-Saturnin tient à l'exploitation de renseignements livrés par un sondage effectué en 1986. Les diverses constatations réalisées permettent d'envisager des hypothèses de travail sur la topographie de l'habitat castrai originel comme sur l'évolution des céramiques des alentours de l'an mil.

\section{Abstract}

Since 1986, a series of complementary investigations bearing on several rural sites in the middle valley of the Herault River has been undertaken in parallel with escavations programmed at the Cisterne at Cabrières (Hérault). Surveys and systematic ground and aerial prospection permit a better understanding of the seulement structures of this micro-region. The case-study undertaken for « Virgin Rock» at Saint-Saturnin results from the exploitation of information delivered by a survey done in 1986 . The different findings suggest several hypotheses as to the topography of the original « castral» habitat or to the evolution of ceramics around the year 1000 A.D.

Citer ce document / Cite this document :

Ginouvez Olivier, Schneider Laurent. Un castrum des environs de l'An Mil en Languedoc central : le Rocher des Vierges à Saint-Saturnin (Hérault). In: Archéologie du Midi médiéval. Tome 6, 1988. pp. 101-122.

http://www.persee.fr/web/revues/home/prescript/article/amime_0758-7708_1988_num_6_1_1170 


\title{
UN CASTRUM \\ DES ENVIRONS DE L'AN MIL EN LANGUEDOC CENTRAL : LE ROCHER DES VIERGES A SAINT-SATURNIN (HERAULT)
}

\author{
Olivier GINOUVEZ * et Laurent SCHNEIDER ** \\ avec la participation d'Armelle GARDEISEN ***
}

\begin{abstract}
Depuis 1986, est entreprise en parallèle avec la fouille programmée de la Cisterne à Cabrières (Hérault), une série dc démarches complémentaires sur d'autres sites des campagnes de la moyenne vallée de l'Hérault. Sondages prospectifs, prospections systématiques au sol et aériennes permettent d'appréhender plus justement les structures du peuplement de cette micro-région. L'étude de cas établie pour le Rocher des Vierges à Saint-Saturnin tient à l'exploitation de renseignements livrés par un sondage effectué en 1986. Les diverses constatations réalisées permettent d'envisager des hypothèses de travail sur la topographie de l'habitat castral originel comme sur l'évolution des céramiques des alentours de l'an mil.

Mots clefs :
\end{abstract}

Castrum, Céramique, Dépotoir, Famille « des deux vierges », Faune, Habitat, Incastellamento, Moyenne vallée de l'Hérault, Tour.

Since 1986, a series of complementary investigations bearing on several rural sites in the middle valley of the Herault River has been undertaken in parallel with escavations programmed at the Cisterne at Cabrières (Hérault). Surveys and systematic ground and aerial prospection permit a better understanding of the settlement structures of this microregion. The case-study undertaken for "Virgin Rock" at Saint-Saturnin results from the exploitation of information delivered by a survey done in 1986. The different findings suggest several hypotheses as to the topography of the original "castral " habitat or to the evolution of ceramics around the year 1000 A.D.

Dans le cadre d'une vaste enquête liée aux problèmes de l'habitat médiéval et du peuplement de type castral dans la moyenne vallée de l'Hérault, nous avons été amenés à construire un programme de recherche, en une région où les centres d'intérêt sur la période médiévale restaient secondaires face à une archéologie presque exclusivement tournée vers l'antiquité.

Aujourd'hui ce travail moins isolé, est lié à un récent projet collectif au sein du programme H. 21 (1).

Localement, cette recherche met en œuvre une série de procédés complémentaires (prospections systématiques, études de textes, sondages et fouilles extensives).

Dans ce sens et en parallèle avec la fouille programmée de la Cisterne à Cabrières (2), sont entrepris plusieurs sondages limités sur des sites voisins afin d'apporter des éléments de datations et de comparaisons aux mobiliers archéologiques et aux différents aménagements rencontrés.

En outre, cette démarche ponctuelle, lorsqu'elle est menée en association avec des fouilles plus extensives, lorsqu'elle s'effectue sur des sites désertés plus précocement ou plus tardivement, permet d'éclairer par compa- ratisme prudent, l'aspect d'un type d'habitat précis à une époque donnée.

Cette approche se justifie d'autant plus, si le site fouillé en extension fait également l'objet d'une étude sur la longue durée. Réaménagements et réoccupations multiples ne font qu'accroître les difficultés de terrain et commandent une recherche parallèle, mais plus restreinte sur d'autres sites saisis dans un environnement social et naturel sinon identique du moins assez proche.

Ces différentes constatations nous ont convaincu en 1986 et 1987 d'engager sur le Rocher des Vierges à Saint-Saturnin une exploration archéologique sous la forme de sondages, de débroussaillage, relevés topographiques et architecturaux.

Dans cette optique, une opération de terrain devait permettre d'appréhender quelques aspects du castrum des environs de l'an mil, sur le rebord méridional du Massif Central, afin de l'opposer plus justement au castrum populatum de la plaine héraultaise.

\section{CADRE GEOGRAPHIQUE.}

Le site castral du Rocher des Vierges, situé au

* $\quad 12$, rue de la Coutellerie, 34800 Clermont l'Hérault.

** Rue Anatole France, Nébian, 34800 Clermont l'Hérault.

*** (Etude de la faune) Laboratoire de préhistoire, Université Paul Valéry (Montpellier III), route de Mende 34100, Montpellier.

(1) Programme H. 21.001 de la sous-direction de l'archéologie: Formes et fonctions de l'habitat castral sur le rebord méridional du massif central, coordination 1988, M.G. Colin, conservatrice à la D.R.A. de Montpellier.

(2) L. Schneider et $\mathrm{O}$. Ginouvez, Archéologie du village déserté en Languedoc central : l'exemple de la Cisterne à Cabrières, Midi, $n^{\circ} 6,1988$ (à paraître). 


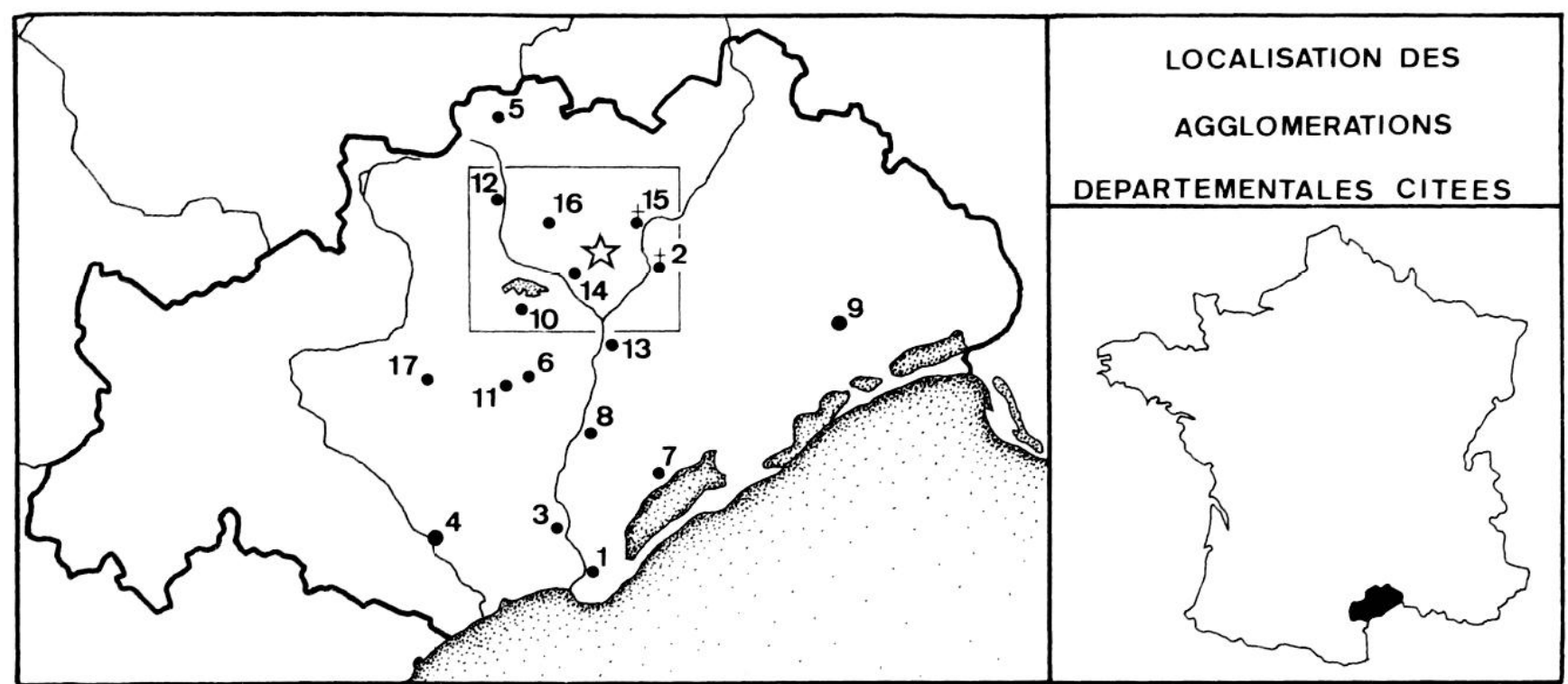

Fig. :1 1: Agde, $2:$ Aniane, $3:$ Bessan, $4:$ Béziers, $5:$ Le Caylar, $6:$ Fontes, $7:$ Mèze, $8:$ Montagnac, $9:$ Montpellier, $10:$ Mourèze, 11 : Neffiès, 12 : Pégairolles de l'escalette, 13: Le Pouget, 14: Saint-Félix-de-Lodez, 15: Saint-Guilhèm-le-Désert, 16: SaintPrivat, 17: Vailhan.

nord-ouest du village de Saint-Saturnin, occupe le sommet d'un bastion géologique isolé se dressant à 536 mètres d'altitude au-dessus du paysage environnant (3). Ce poste naturel se détache nettement parmi les contreforts qui épaulent au sud le Causse du Larzac. Il occupe de ce fait un emplacement inégalable, entre les plateaux de l'arrière-pays Languedocien venant buter au nord-est contre la chaîne de la Sérane et, le bassin médian de l'Hérault visible jusqu'au confluent du fleuve avec la Lergue.

Son emplacement, résultant d'un cadre physique extrêmement favorable assure d'emblée au site une vocation de vigie sur la partie nord de la moyenne vallée de l'Hérault au sud-est, de sa communication avec le Causse - actuelle R.D. no 9 - au nord et, sur la vallée de la Lergue, à l'ouest, avec la voie de pénétration Clermont-l'Hérault-Lodève-Le Caylar - actuelle R.N. no 9.

\section{ARCHITECTURE.}

\subsection{Organisation topographique du bâti.}

D'origine jurassique, la saillie du Rocher des Vierges est couronnée par une émergence de roches dolomi-

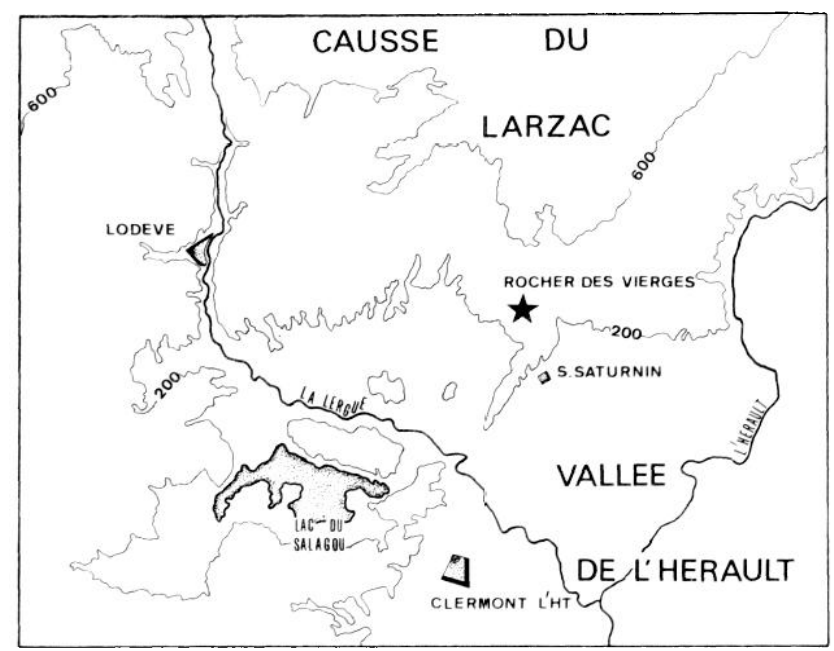

Fig. 2 : Cadre géographique du site du Rocher des Vierges.
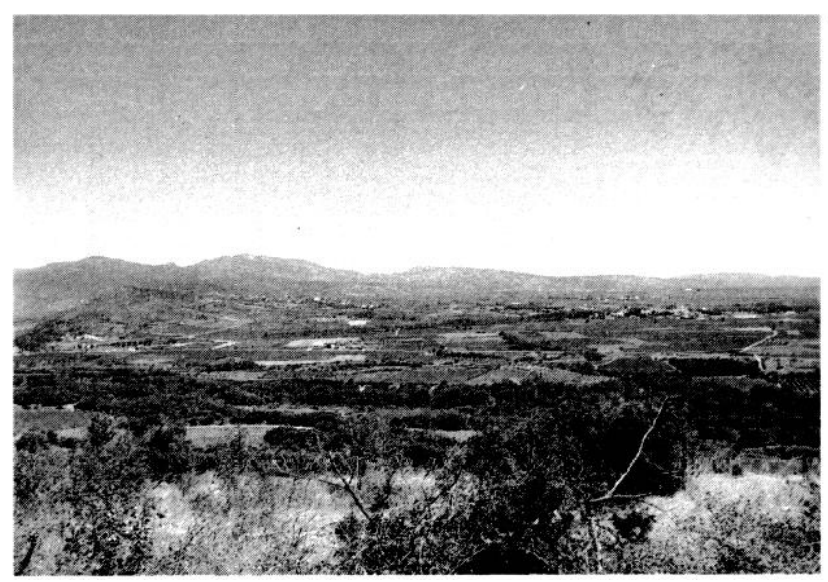

Fig. 3 : Le Rocher des Vierges : une zone de contact entre plaine littorale et Massif Central.

tiques dont l'incidence sur la topographie de l'habitat sera prépondérante. Ce relief ruiniforme est entaillé de failles profondes qui ont pour certaines reçu fonction d'accès vers une plate-forme sommitale limitée de part et d'autre par des falaises ou de brusques ruptures de ni-

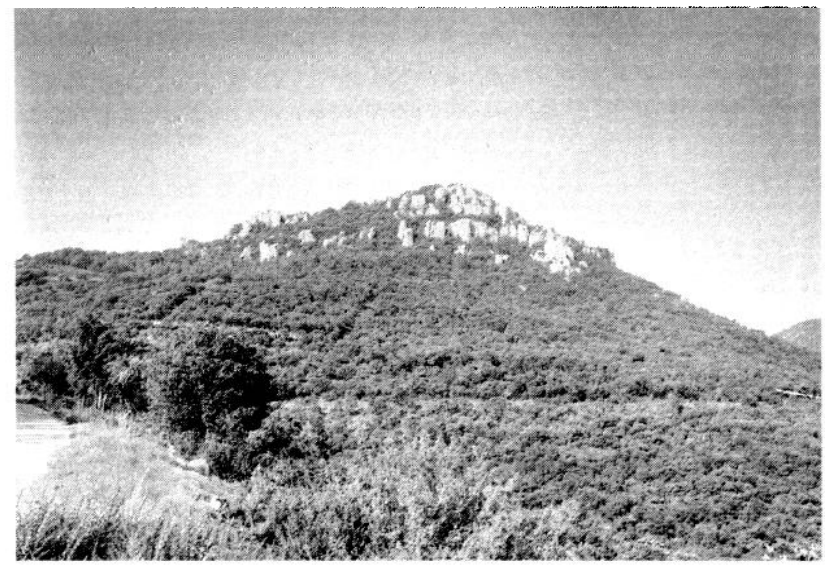

Fig. 4 : Le Rocher des Vierges, vue est.

(3) Coordonnées Lambert III : X : 690,625. Y : 3157, 750. Z : 536 (Carte IGN 1/25000, feuille de Clermont-l'Hérault 2643 est). 


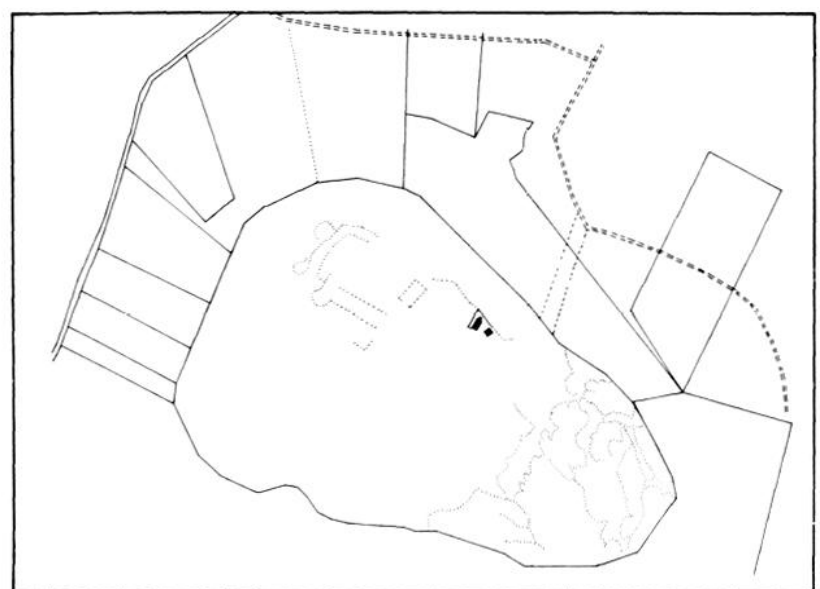

Fig. 5 : Extrait cadastral : Saint-Saturnin, parcelle 154, section A 3, 1953, révisé pour 1981 .

veaux sous forme de pendages plus ou moins accentués.

Cette plate-forme sommitale couvrant près de $1500 \mathrm{~m}^{2}$ est divisée en deux espaces distincts, d'égale superficie, par une large faille profonde en moyenne de six mètres.

La première zone au sud (fig. 6) est immédiatement accessible par un étroit chemin calladé ayant entaillé le rocher par endroits. Le sol y est occupé par un abri d'origine contemporaine, une chapelle orientée ainsi que par les fondations d'une tour circulaire bâtie au nord, en bordure du fossé naturel.

La chapelle, actuellement désignée sous le vocable de Saint-Fulcran, est la seule architecture mentionnée dans les textes. En 1160, il en est fait état sous le vocable Sainte-Marie dans le testament de Guiraud de Touroulle (4). Le lieu de culte, dont la raison d'être est sans doute castrale est ensuite inscrit en 1331 dans la liste de l'évêque Bernard Gui, comme annexe de l'église paroissiale de Saint-Saturnin (5). La construction est modeste. La nef unique, avec contreforts soutenant les murs gouttereaux, est terminée à l'est par une abside semicirculaire. L'appareil des murs, peu soigné, non assisé, suggère une origine moderne. Dans ce cas, le sanctuaire médiéval a pu servir de substruction à l'édifice actuel, celui-ci respectant un plan d'origine romane.

La tour circulaire très arasée qui s'élève à proximité constitue une très puissante maçonnerie dont le diamètre est proche de huit mètres. Fondés à même le substrat, ses murs sont assisés régulièrement à l'aide de gros moellons de calcaire ébauchés et liés par des joints gras. L'espace intérieur y est de forme quadrangulaire.

Le caractère isolé de cette tour - la structure visible à l'ouest est venue s'accoler postérieurement au parement - ainsi que ses fortes proportions autorisent l'emploi à son sujet du terme de donjon.

Ce premier ensemble ne semble pas avoir été établi dans un périmètre totalement clos. Seuls les endroits stratégiques ou les bordures limitées par des pentes à faible pendage ont reçu un aménagement. Le lit supérieur d'une construction est visible au sud devant l'abri ainsi qu'au nord-est entre le parement de la tour et l'abside de la chapelle. Dans les deux cas, il semble s'agir des vestiges d'une clôture, percée d'une porte, venue barrer un accès à la pente danś le premier cas, au fossé naturel dans le second cas.

Un mur vient enfin limiter l"espace de la place à l'ouest. Sa faible épaisseur n'en fait toutefois pas un élément de fortification. Il est plus raisonnable de lui attribuer une fonction de soutien à la terrasse.

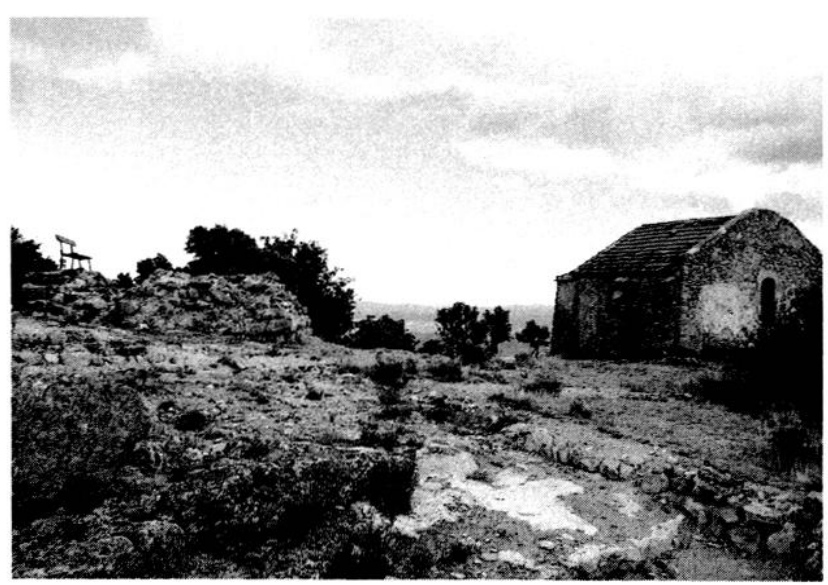

Fig. 6 : Zone $n^{\circ} 1$, vue nord-ouest.

La seconde zone (fig. 7) ne présente aucune construction en complète élévation. De plus, l'épaisse végétation qui occupe la majeure partie du sol interdit toute observation de possibles structures arasées.

Sur le rebord sud et faisant face au donjon circulaire ont été révélés par la fouille les soubassements d'une tour quadrangulaire apparemment isolée.

Ces fondations, épaisses de $95 \mathrm{~cm}$ au niveau du dernier lit de pose conservé, sont constituées de trois côtés bâtis venant s'appuyer à l'est sur le rocher retaillé afin de composer le quatrième côté. Dégagées sur 2,50 mètres de hauteur, elles présentent un net empâtement associé à une augmentation progressive du volume des matériaux employés (fig. 9). Le tout repose sur deux assises en aplomb débordantes. La force qui se dégage de cette fondation permet d'imaginer une tour élevée envers laquelle l'on est à nouveau tenté d'utiliser le qualificatif de donjon.

A la différence de la première zone, un mur, large d'un mètre, vient border la ligne occidentale du plateau dans la partie où celle-ci est la plus vulnérable (fig. 10). Sur une longueur de 18 mètres cette enceinte est un complément nécessaire aux limites naturelles moins marquées de ce côté. Les formes du rocher, volontairement utilisées, ont imposé à la direction rectiligne du parement, un tracé brisé par un angle rentrant et deux saillies curvilignes.

Sans nier le rôle évident de protection joué par cette construction, il faut doubler celui-ci d'une fonction de soutènement venant contrebuter les poussées exercées par une terrasse haute en moyenne de 2 mètres.

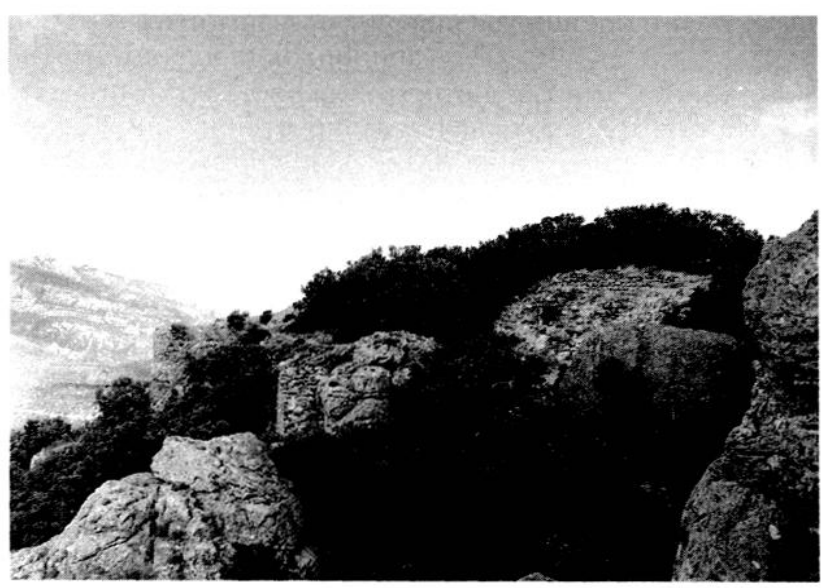

Fig. 7 : Zone $n^{\circ} 2$, vue sud.

(4) O. Terrin, Cartulaire du chapitre d'Agde, Nîmes, 1969, c. no 144, p. 140.

(5) J. Rouquette, Cartulaire de l'église de Lodève : Livre Vert, Montpellier, 1923, p. 27. 


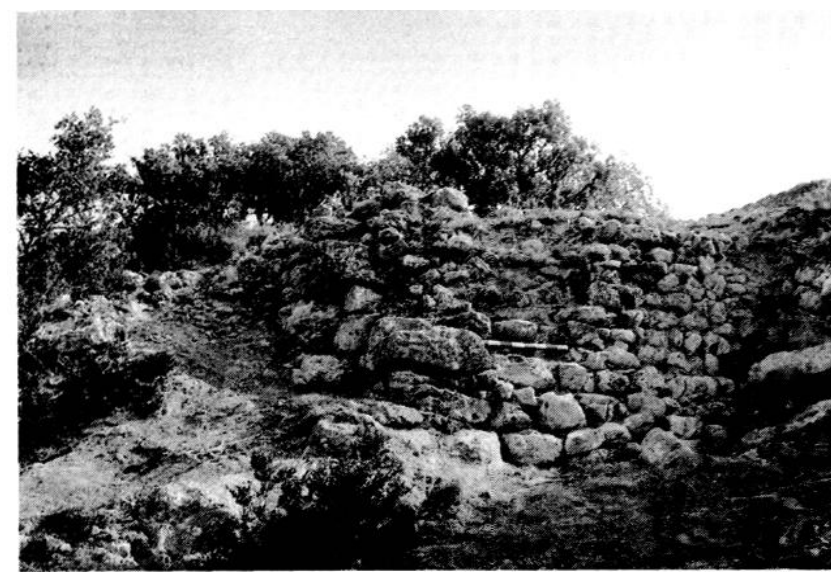

Fig. 8 : Fondation extérieure de la tour, angle sud-ouest.

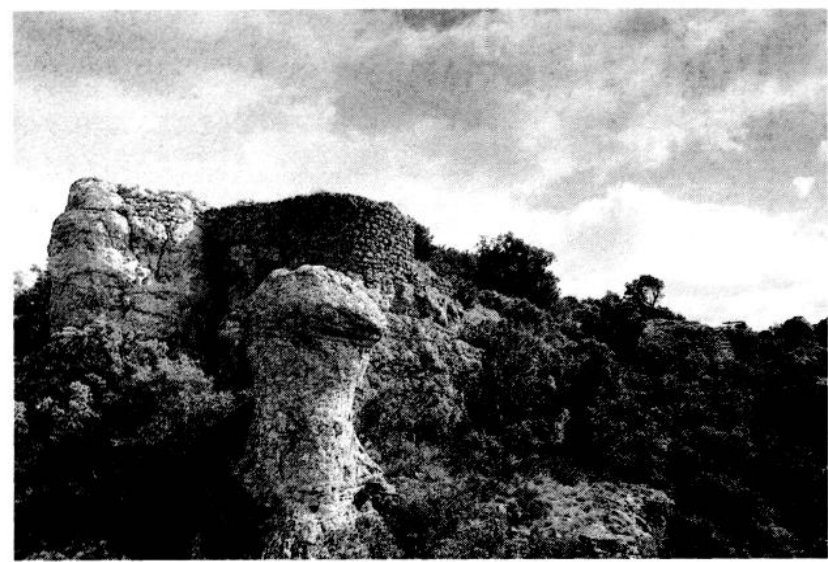

Fig. 9: Mur ouest: un complément nécessaire aux limites naturelles.

L'élévation du mur, aujourd'hui arrêtée au niveau du sol de la plate-forme est impossible à restituer.

De cet ensemble tour-enceinte somme toute homogène du point de vue des techniques de constructionmoellons de calcaire, parfois ébauchés, disposés en assises irrégulières liées à l'aide de joints gras - se distinguent au nord, en contrebas, les vestiges d'un mur percé d'une pörte qui vient barrer une faille donnant accès par une forte pente à la seconde plate-forme.

L'arc, aujourd'hui disparu, couvrant l'ouverture venait s'appuyer d'une part sur la maçonnerie subsistante, d'autre part sur le rocher aménagé à cet effet. L'appareil des parements préservés est constitué de moellons à têtes dressées, hauts en moyenne de dix centimètres, disposés en assises régulières (fig. 10 et 11).

Cettc différence dans l'art de bâtir, d'autant plus marquante qu'elle fait figure d'exception sur le site, demeure énigmatique. Peut-on l'expliquer en lui attribuant une antériorité sur toutes les autres structures du castrum visibles par ailleurs? Le problème reste posé.

\subsection{Synthèse.}

Le cas du castrum du Rocher des Vierges représente un type d'habitat fortifié tout à fait rare dans notre région. Rare d'abord dans le choix de l'emplacement élevé et isolé par rapport à la plaine et ses villae, rare ensuite par son organisation. Si celle-ci est inhérente à la topographie du site, l'adaptation des aménagements

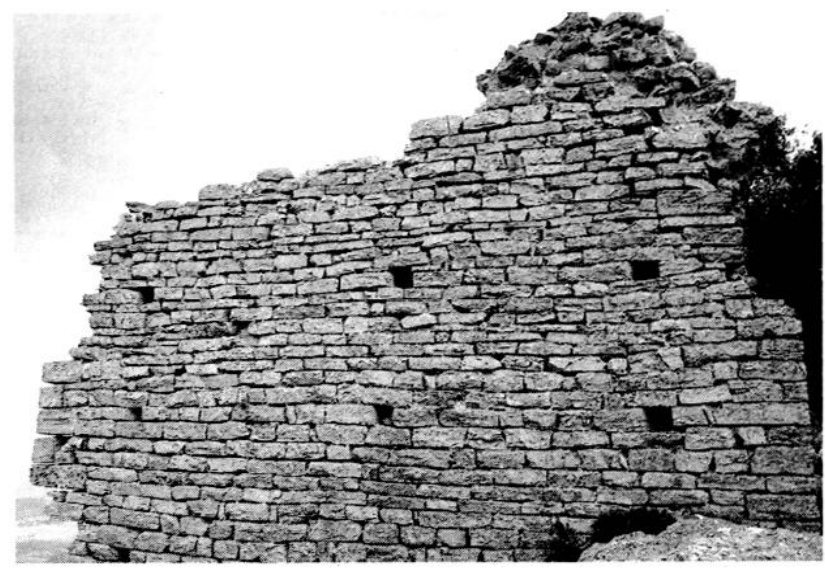

Fig. 10 : Porte nord.

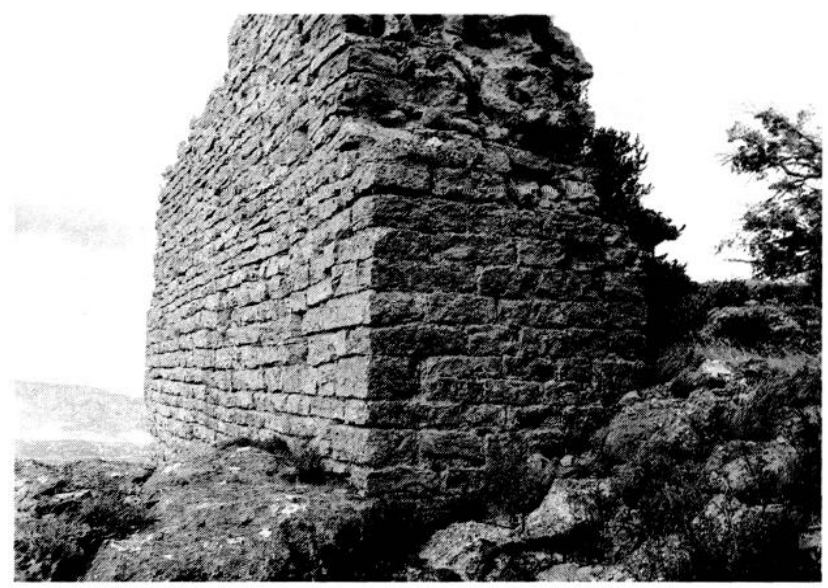

Fig. 11: Porte nord, vue rapprochée.

humains au milieu physique n'en demeure pas moins originale.

Pas de clôture continue enveloppant la totalité de la place. A prévalu le désir d'une fortification « parasite », profitant au maximum d'un relief dont les défenses naturelles ont été complétées sans être doublées.

En résulte un castrum d'aspect non classique où les murs jouent et finissent par se confondre avec le rocher.

Seuls deux exemples régionaux présentent quelques analogies dans leur mode d'occupation avec le Rocher des Vierges. Il s'agit des castrums de Mourèze et du Caylar, tous deux implantés sur des roches de nature dolomitique.

L'étude architecturale ayant permis d'individualiser - les groupes construits met en évidence la dualité exprimée par la présence des deux tours/donjons. Cette dualité que l'on peut être tenté de rapprocher de celle évoquée dans le toponyme castral (6) pose de fait un problème. La traduire en en faisant la résultante d'une coseigneurie demeure hypothétique. Les textes sont muets à ce propos. En outre, la traduction de cette situation politique dans la réalité matérielle d'un habitat castral reste souvent mal connue.

L'explication la plus plausible semble être de considérer l'une des tours comme antérieure à l'autre. Nous remarquons en effet que la tour quadrangulaire du Rocher des Vierges s'apparente bien que très arasée au type de donjon-corps de logis omniprésent dans l'archi-

(6) Selon l'historiographie traditionnelle (A. Durand, Histoire de la ville de Clermont-l'Hérault et de ses environs, Lodève, 1837, p. 9) deux sœurs de l'évêque de Lodève, Saint Fulcran (949-1006) venues se retirer pour prier Dieu sur le rocher seraient à l'origine du toponyme médiéval et actuel. Les textes médiévaux ne font jamais référence à ce fait. On peut toutefois remarquer, élément troublant, que les dates de l'épiscopat de Saint Fulcran correspondent à la fourchette de construction établie pour le castrum. 
tecture militaire du premier âge féodal méridional. Cette forme d'habitat massif et bien bâti se retrouve plus ou moins bien préservée dans d'autres sites castraux régionaux comme Lodève (7), Saint-Privat ou Pégairolles de l'Escalette.

Dans cette optique, la tour circulaire ne serait qu'une addition au système défensłf primitif. Le mobilier exhumé dans les soubassements de la tour fouillée n'est pas postérieur au XI $\mathrm{X}^{\mathrm{e}}$ siècle. Celle-ci est-elle abandonnée à cette date pour la nouvelle construction édifiée à proximité ? Les deux tours ont-elles fonctionné contemporainement à une époque donnée? Les renseignements émanant de l'étude sur le terrain et des textes ne nous permettent pas de soutenir l'une ou l'autre des possibilités.

\section{CONTEXTE HISTORIQUE.}

\subsection{Premières mentions.}

Le premier texte témoignant d'une occupation médiévale sur le Rocher des Vierges est daté du 11 novembre 1004. Il s'agit d'une charte du cartulaire de Gellone dans laquelle est fait état d'un manse et d'un apendaria situés in suburbio castri Duas Virgines (8). Mentionnée relativement tôt, la demeure fortifiée dont il est question ne correspond pas pour autant à la première présence humaine sur les lieux. Les prospections effectuées sur les pentes de l'éminence ont permis de recueillir en surface des témoins céramiques remontant au second âge du fer et; de localiser au pied du rocher dolomitique un

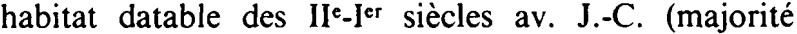
d'amphores Dressel 1 A et 1 B) (9).

Le caractère précoce d'une activité humaine sur le site tend à confirmer son rôle, déjà évoqué, dans le contrôle des voies de communication naturelles utilisées dès la protohistoire (10).

Un fragment de sigillée sud-Gauloise (Drag. 29) provenant de la plate-forme sommitale autorise à prolonger cette activité jusqu'au Ier siècle après J.-C. Le Rocher des Vierges semble, à partir de cette date, abandonné jusqu'aux $\mathrm{X}^{\mathrm{e}}-\mathrm{XI}^{\mathrm{e}}$ siècles.

Il va sans dire que le texte de 1004 ne répond en rien à la question soulevée par la date de construction du castrum. Une charte du même cartulaire de Gellone pourrait résoudre en partie ce problème en offrant un terminus post quem. Dans cet écrit daté du 27 juillet 930, un certain Armandus donne à l'abbaye un manse situé dans le terminium de la villa appellée Malos Albergos, sans plus de précisions (11). Le texte de 1004, déjà cité, présente quant à lui un dénommé Raimundus confiant à Gellone un manse et un apendaria situés dans la même villa de Malos Albergos définie cette foisci in suburbio castri quem vocant Duas Virgines.
Il est raisonnable de supposer qu'en 930 le castrum n'existait pas encore. Il aurait sinon servi, comme dans le texte de 1004 et suivant un usage respecté à cette époque, de point de repère monumental précieux à la localisation des terres habitées ou cultivées environnantes.

Nous placerions donc la construction du castrum des Deux Vierges dans une fourchette de 74 ans, entre les années 930 et 1004.

\subsection{Le lignage des « des Deux Vierges ».}

Qui sont les maîtres du lieu-dit fortifié ? Nous connaissons leur anthroponyme apparaissant pour la première fois en 1026 dans un acte du cartulaire d'Aniane. En cette année, Pierre de Gignac donne à l'abbaye la moitié de l'église Saint-Pierre de Gignac, cum consilio, entre autres, de Berenger Willerm des Deux Vierges (12). Le nom de lieu précédé du prénom suivi lui-même du prénom du père détermine la provenance mais aussi et surtout le fait que la personne est châtelaine propriétaire ou gardienne d'un castrum. Il est plus ardu pour ne pas dire impossible de retrouver les origines de cette famille et d'entrevoir ses liens avec les autres lignages nobiliaires de la contrée. En ce qui concerne l'émergence des « des Deux Vierges » les possibilités d'explication se réduisent à deux éventualités. Soit leur autorité est un héritage d'origine vicomtale, soit le pouvoir banal qu'ils semblent détenir a été usurpé afin de constituer une châtellenie indépendante. Le castrum et ses habitants étant mentionnés très tôt dans le contexte castral régional nous pencherions pour la première solution.

Au cours des XIe-XIIIe siècles, les « des Deux Vierges " sont présents dans le vie politique, sociale et religieuse de la vallée de l'Hérault et du rebord méridional du plateau du Larzac (13).

Les nombreux dons de manses, de villae, d'églises aux abbayes d'Aniane, de Gellone ou au Chapitre d'Agde prouvent l'importance de leurs possessions foncières et leur conscience d'appartenir à une aristocratie de premier plan. En 1007-1099, Petrus Gaucelmi filius ex castro que vocant Duas Virgines donne la villa Francigeni Lacus (située sur le plateau du Larzac (14) à l'abbaye de Gellone afin que les moines y construisent une église. Il donne par la même occasion la terre occupant un périmètre de trente pas autour du sanctuaire afin que les moines y installent leurs habitations (15).

Le 21 juillet 1137, Ermengaud des Deux Vierges cède à Raimond, évêque d'Agde, la tierce sur la dîme de Mèze (16). Les exemples de ce type, démontrant la variété géographique des biens de la famille des «des Deux Vierges " sont nombreux. En 1160, le castrum est en possession de Guiraud de Touroulle (17), frère de

(7) P. Delon, Le Château de Montbrun à Lodève (Hérault). Etude historique et sondages stratigraphiques, Archéologie en Languedoc, 1985 (4), (1986), pp. 161-174.

(8) P. Alaus, A. Cassan et E. Meynal, Cartulaire de Gellone, Montpellier, 1900, c. XXXVII, p. 38.

(9) Cet habitat a été en partie éventré en 1986 lors de la réalisation d'un chemin d'accès par le service des eaux et forêts.

(10) D. Garcia, L'Age du Fer dans la Moyenne Vallée de l'Hérault, Etudes sur l'Hérault, N.S. 2-3, 1986-1987, pp. 19-24.

(11) P. Alaus, A. Cassan et E. Meynal, op. cit., c. XXXVI, p. 37.

(12) A. Cassan et E. Meynal, Cartulaire d'Aniane, Montpellier, 1900, c. CCXXIII, p. 354.

(13) Certains membres de la famille des Deux Vierges sont fréquemment cités en tant que protagonistes ou témoins dans de nombreux actes des cartulaires d'Aniane et de Gellone : A. Cassan et E. Meynal, op. cit., c. XIII, p. 146, c. XXII, p. 158, c. XXIII, p. 160 , c. XXIV, p. 161, c. LI, p. 192 , c. CXIX, p. 202, c. LXXXII, p. 220, c. CVIII, p. 250, c. CXLVI, p. 285, c. CLXXXIV, p. 324 , c. CCXXIII, p. 354 , c. CCXXVII, p. 357 et c. CCCXXXVI, p. 448.

P. Alaus, A. Cassan et E. Meynal, op. cit., c. XXXVII, p. 38, c. CLXXXIX, p. 166, c. CLXXXX, p. 167, c. CLXXXXI, p. 167 , c. CCXIII, p. 183 , c. CCLVI, p. 125, c. CCCCLXXXX, p. 397, c. CCCCLXXXXIII, p. 403, c. CCCCLXXXXVIII, p. 407 et c. DXXXXVII, p. 470 .

(14) G. Combarnous, Index de noms de lieux et de personnes dans le cartulaire de Gellone (Abbaye de St-Guilhem), Clermontl'Hérault, 1975, p. 37.

(15) P. Alaus, A. Cassan et E. Meynal, op. cit., c. CCXIII, p. 183.

(16) J. Rouquette, Cartulaire de l'église d'Agde : cartulaire du chapitre, Montpellier, 1925, c. CX, p. 126.

(17) Le château de Touroulle était situé dans l'actuelle commune de Bessan (34). 
Guillelm des Deux Vierges (18).

Dans le domaine religieux, deux membres de la famille sont abbés de Gellone, le premier de 1137 à 1141 (19), le second de 1249 à 1289 (20). Un certain Guillelm des Deux Vierges, chanoine, est fréquemment cité comme témoin d'actes passés avec le chapitre de l'église d'Agde, dans les années 1204-1215 (21).

Nous ne connaissons pas les liens qui unissent les «des Deux Vierges» aux familles nobles régionales. Monique Bourin émet la possibilité qu'ils aient appartenu aux mêmes lignages que les châtelains de Clermontl'Hérault et Fozières (22). Leurs descendance directe semble s'être éteinte assez tôt, peut-être dès le XIV ${ }^{c}$ siècle. En 1462, le roi Louis XI donne à Philippe de Deux Vierges, seigneur de Montpeyroux, la charge de viguier de Roussillon et de Valespir (23). Sans doute, faut-il voir à cette date les possessions des « des Deux Vierges » passées par héritage à la lignée des Montpeyroux mentionnée quant à elle depuis le XIIe siècle (24).

\subsection{Le Rocher des Vierges : quel type d'habitat ?}

Sans revenir en détail sur la situation et l'environnement géographique du Rocher des Vierges, il nous faut introduire, préalable nécessaire à toute analyse sur l'occupation des sols, la précision suivante. Le castrum est bâti sur un avant-poste vers l'ouest de la zone de garrigues nord-Montpelliéraine mise en évidence par Aline Durand (25), plus précisemment en un espace frontalier marquant la limite avec l'aire Bittéroise définie par Monique Bourin (26).

Ces deux entités, différentes de par leur relief, leur végétation et leur climat ont révélé une évolution et une organisation quelque peu différente face à l'incastellamento.

En ce qui nous concerne, Aline Durand constate après une étude fondée principalement sur les textes du cartulaire d'Aniane, que le castrum nordMontpelliérain n'a jamais été, jusqu'au début du XIII ${ }^{e}$ siècle, un̉ foyer de peuplement. Dans le sèns de son analyse, c'est la villa, fortifiée dans certains cas dès le $\mathrm{X}^{e}$ siècle, qui a favorisé à partir de la fin du XI' siècle le regroupement des hommes.

Possédant une église, à l'origine du statut paroissial, elle était le véritable centre économique placé aux abords immédiats des voies de communication.

Le cas du castrum des Deux Vierges correspond bien aux constatations émanant des textes. Les prospections systématiques effectuées sur le site et ses abords permettent d'affirmer l'absence de tout habitat villageois. Ceci confirme une fonction de type uniquement aristocratique et militaire à la fortification, et ce durant toute sa période de fonctionnement.

En 1067, apparaît la paroisse, S. Saturnini de Lucano (27) réunie sans doute autour d'une ancienne église domaniale. Situé deux kilomètres au sud du castrum ce regroupement dont nous ne connaissons pas les relations avec la famille des « des Deux Vierges » est à l'origine de l'actuelle agglomération de Saint-Saturnin.

\section{LES DONNEES DU SONDAGE.}

Les prospections effectuées sur le site dès l'année 1985, avaient permi de localiser un point précis du gisement susceptible de constituer rapidement une base de données propice à l'étude des phases d'occupation et de fonctionnement de l'ensemble archéologique.

La zone, comprise dans le niveau de soubassement de la tour quadrangulaire, livrait en surface un abondant mobilier riche en fragments de céramique et de restes osseux. Le sondage a donc volontairement porté sur l'étendue totale de cette aire délimitée sur trois côtés par un bâti et par la paroi du rocher sur le quatrième.

\subsection{La stratigraphie.}

\subsubsection{Description (fig. 13)}

U.S. 1001. Couche de terre limoneuse et meuble de couleur grise.

U.S. 1002. Couche de terre limoneuse et meuble de couleur noire.

U.S. 1003. Couche de terre limoneuse et meuble de couleur jaune.

U.S. 1004. Couche de terre limoneuse et meuble de couleur grise.

U.S. 1005. Niveau de gros moellons et de blocs de calcaire froid suivant un fort pendage ouest/est.

U.S. 1006. Couche de terre grise limoneuse et caillouteuse à consistance meuble.

\subsubsection{Interprétation.}

Les quatre Unités Stratigraphiques 1001, 1002, 1003 et 1006 sont homogènes et contenaient, comme l'U.S. 1004, un abondant mobilier archéologique - céramiques de cuisine, fragments de tuiles canal -.

A notre arrivée, l'espace intérieur de la tour présentait une forte déclivité dans sa partie est. Cette constatation, confirmée par certaines remarques effectuées lors de la fouille, donne à penser que cette partie avait fait l'objet à une date inconnue d'un bouleversement consécutif à un probable sondage clandestin.

Délimitée côté sud et ouest par le substrat vertical -retaillé par endroits - cette excavation a été pratiquée jusqu'au niveau supérieur de l'U.S. 1006. L'U.S. 1005 est un fait résultant de cette intervention - rebouchage rapide -. Dans ce contexte, l'U.S. 1004 est un niveau hétérogène, de formation récente, dû au glissement - érosion et infiltration - de l'extrémité est des U.S. 1001 et 1003 , à consistance très meuble.

L'interprétation des Unités Stratigraphiques mises au jour lors du sondage de 1986 est somme toute aisée. Les niveaux $1001,1002,1003$ et 1006 ne présentaient aucune compaction de surface. Leur position les uns par rapport aux autres, leur qualité, leur texture, enfin les matériaux qu'ils contenaient affirment la présence d'un dépotoir formé de recharges successives provenant des déchets d'une activité domestique, jetées régulièrement dans un laps de temps limité.

(18) O. Terrin, op. cit., c. no 144 , p. 240

(19) H. Fisquet, La France pontificale (Gallia christiana), Montpellier, non daté deuxième partie, p. 489.

(20) H. Fisquet, op. cit., p. 497

(21) O. Terrin, op. cit., c. $\mathrm{n}^{\circ} 7$, p. 16, c. $\mathrm{n}^{\circ} 101$, p. 104, c. $\mathrm{n}^{\circ} 103$, p. 106 et $\mathrm{n}^{\circ} 118$, p. 118.

(22) M. Bourin-Derruau, Villages médiévaux en bas Languedoc: genèse d'une sociabilité (X'-XIVe siècles), Paris, 1987, tome 1, p. 79 , note 12 .

(23) Dom C. Devic et Dom J. Vaissette, Histoire Générale de Languedoc, Toulouse, 1889, T. XI, p. 48.

(24) Dom C. Devic et Dom J. Vaissette, ibid. p. 798.

(25) A. Durand, Regroupement des hommes et création du maillage paroissial dans la garrique nord-montpelliéraine aux $\mathrm{X}^{\mathrm{c}}$-XII ${ }^{\mathrm{c}}$ siècles d'après le cartulaire d'Aniane, $110^{\circ}$ Congrès National des Sociétés Savantes, Paris, 1985, pp. 271-286.

(26) M. Bourin-Derruau, op. cit.

(27) P. Alaus, A. Cassan et E. Meynal, op. cit., c. LVIII, p. 55. 


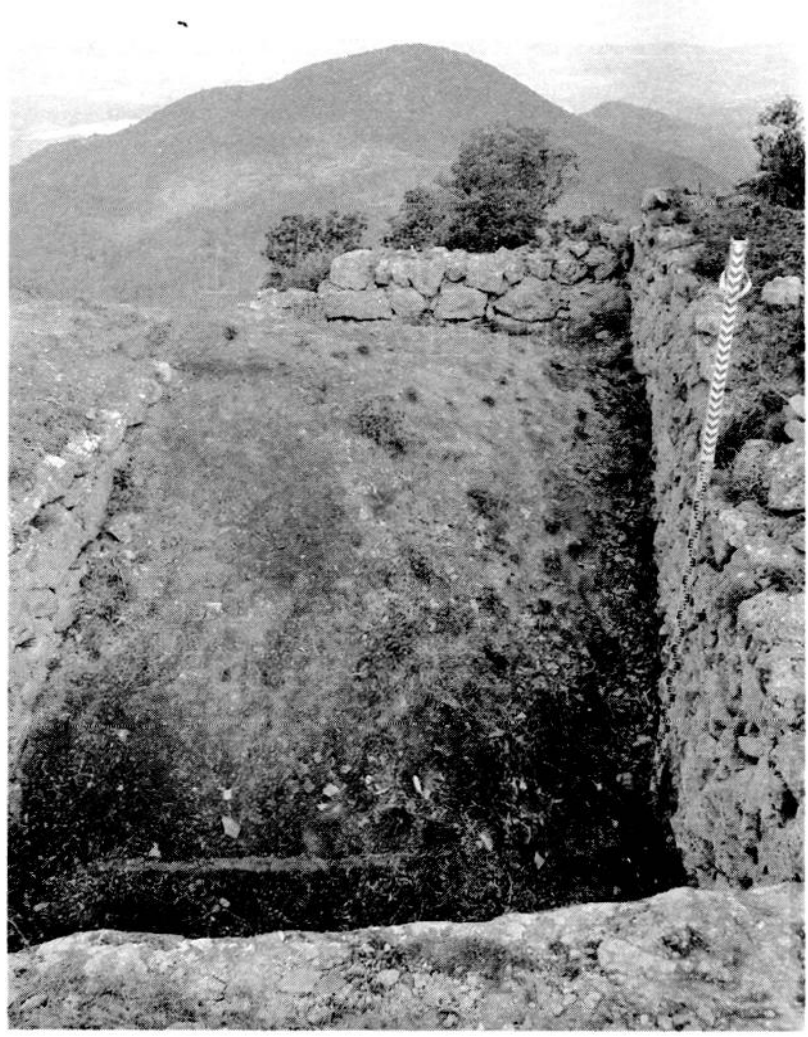

Fig. 12: Les soubassements de la tour avant la fouille, vue ouest.

\subsection{Le mobilier céramique.}

Les sédiments contenus dans le dépotoir de la tour ont livré un mobilier céramique homogène et abondant qui fournit un repère chronologique précieux en accord avec celui des textes.

L'étude de cette céramique est pourtant en Languedoc et, plus particulièrement en Languedoc central, un problème délicat tenant à la rareté des séries publiées comme au faible avancement des recherches en céramologie et sur l'habitat médiéval lui-même. Cette constatation, leitmotiv permanent des chercheurs régionaux oblige à une nécessaire prudence dans les datations proposées.

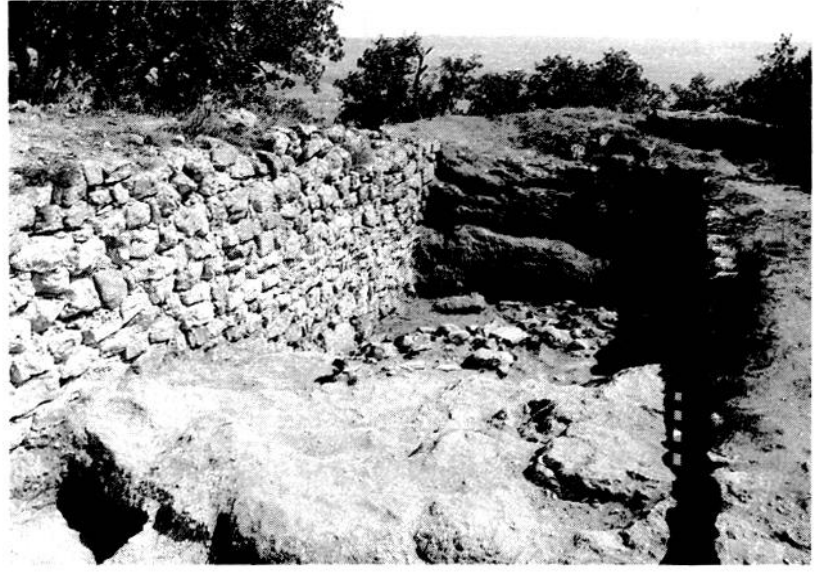

Fig. 14: La fouille en cours. Au premier plan le substrat.

Celles-ci sont en effet et pour cause toujours tributaires de comparaisons empiriques, d'observations ponctuelles elles-mêmes liées à l'absence d'études basées sur des séquences stratigraphiques précises. Il faut encore faire largement appel à celles réalisées dans d'autres départements alors que le caractère régional ou non de notre échantillonage n'est toujours pas défini.

De ce fait, l'étude du matériel céramique de SaintSaturnin n'est envisageable que dans la perspective d'hypothèses d'évolution et de repères chronologiques larges.

\subsubsection{Analyse descriptive.}

Le mobilier est composé d'un ensemble de 982 fragments sériables en deux grandes catégories : céramiques oxydantes et céramiques réductrices.

L'observation des formes ne permet pas de distinguer une utilisation, une fonction particulière des céramiques en liaison avec leur type de cuisson. Les remarques effectuées sur les mottes du Mourel à Molleville et de Puy Redon à Laurac (28) ne trouvent pas d'équivalents dans nos séries puisque les céramiques grises, majoritairement représentées par des pots à cuire ou à conserver, peuvent également constituer des vases à liquide.

Ce sont les pourcentages relatifs à ces deux grandes catégories qui permettent de comparer notre échantillonage à plusieurs ensembles languedociens.

A Saint-Saturnin la céramique réductrice demeure

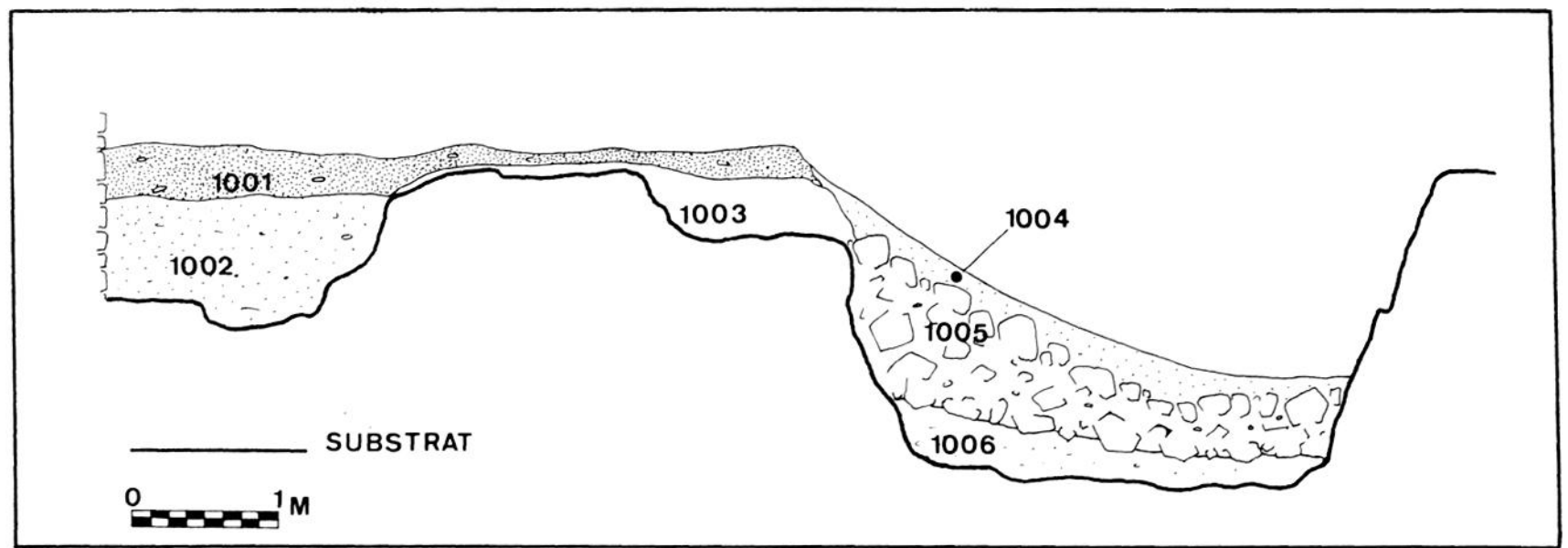

Fig. 13 : Coupe stratigraphique ouest-est.

(28) M. Dauzat, La motte du Mourrel à Molleville et la motte de Puyredon à Laurac (Aude), Archéologie du Midi Médiéval, 2, 1984, pp. $27-45$. 
ARCHEOLOGIE DC MIDI MEDIEVAL - TOME VI - 1988.
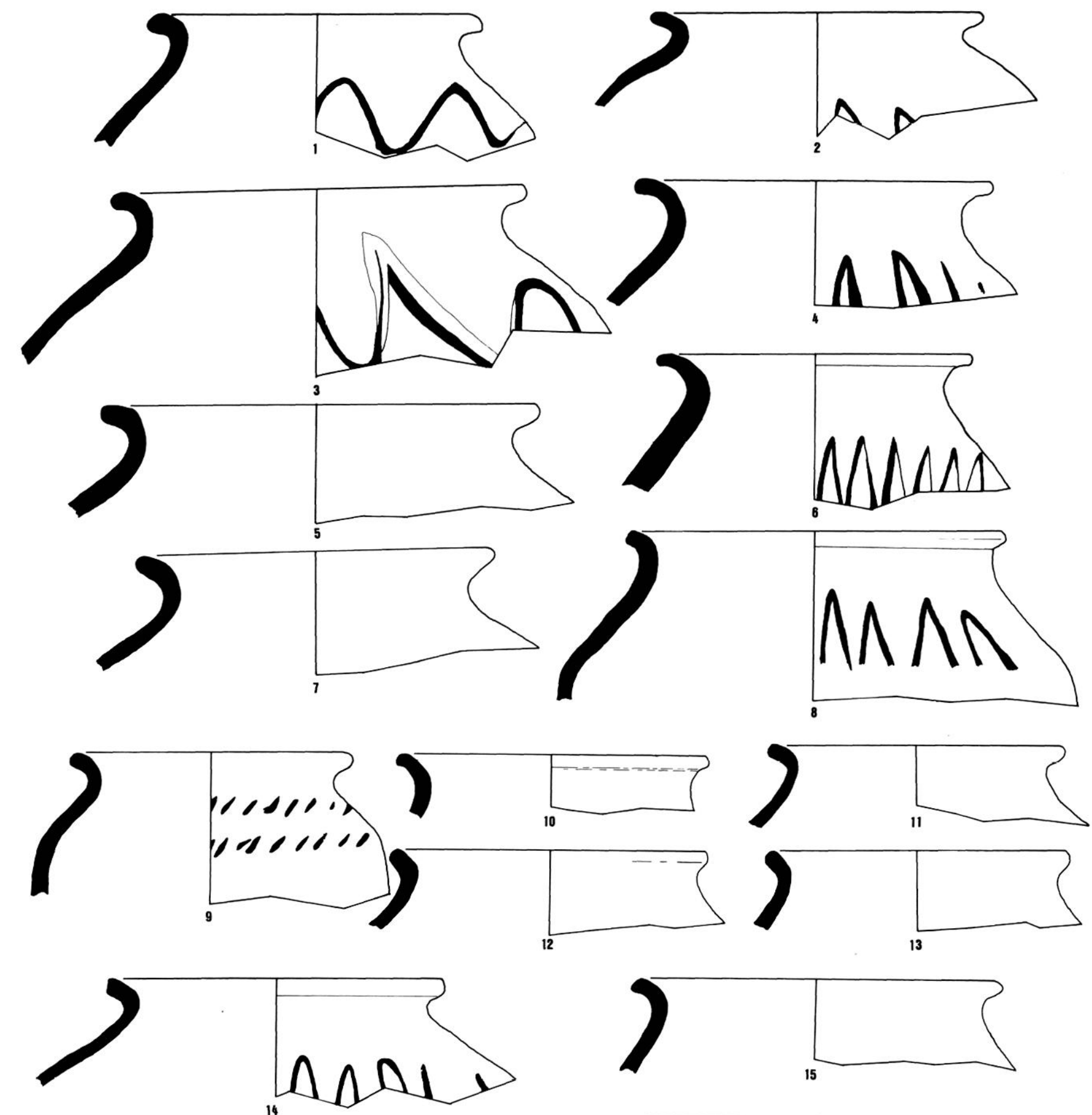

14
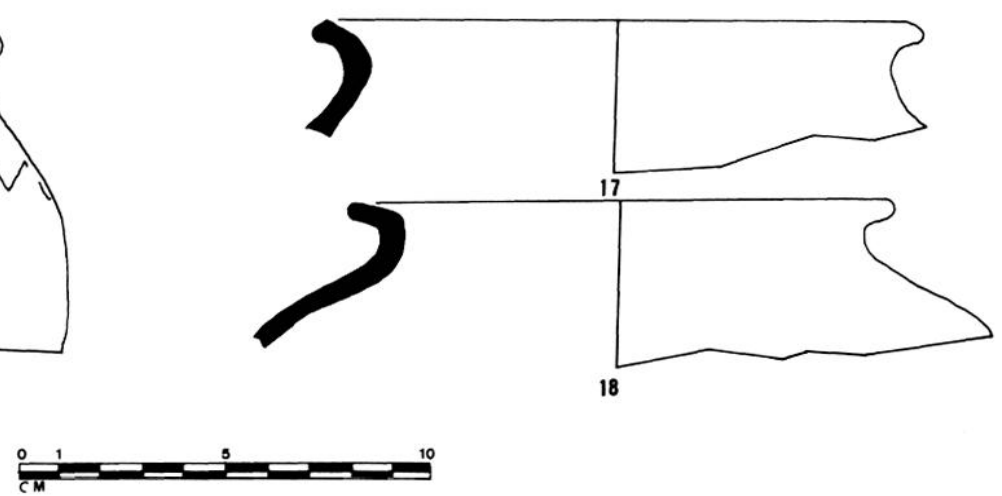

Fig. 15: Céramiques réductrices non polies.

108 
abondante avec $85,94 \%$ contre $14,06 \%$ pour la céramique oxydante. Ce résultat est à rapprocher des observations effectuées à Saucani pour la région immédiate (29) puisque $80 \%$ des tessons découverts appartiennent au premier groupe, mais aussi avec ceux du Mourrel, de Puy Redon (74,47\%) (30), de Saint-Andrieu (72,33\%) (31) dans l'Aude et, de Montaigut dans le Tarn $(83,45 \%)(32)$.

Le terme générique de céramique commune que l'on assigne traditionnellement à ce type de matériel recouvre ici plusieurs fabrications d'origine diversifiée. Il semble possible de discerner une céramique fine dans le type oxydant (fig. 17, $\mathrm{n}^{\text {os }} 6,15$ et 16) certes minoritaire et jusqu'à présent sans équivalent sur les sites régionaux récemment découverts ( 33 ).

A côté des deux grands types de cuisson (oxydant et réducteur) il existe des variantes résiduelles : oxydante à post-cuisson réductrice ou céramique à pâte beige ocrée. Ces distinctions imputables à des techniques de cuisson différentes doivent aussi être associées à la diversité qualitative et d'origine des argiles utilisées.

Si la stratigraphie ne permet guère de séparer chronologiquement ces productions, l'étude comparative fait apparaître un nouveau groupe. Celui-ci représente $2,13 \%$ des tessons découverts. Il s'agit d'une céramique à pâte calcaire beige ocrée avec traces de polissage systématique sur la surface extérieure (fig. $17, \mathrm{n}^{\text {os }} 18,11$ et 12).

La totalité du matériel étudié appartient à un répertoire des formes très restreint : vases fermés globulaires. Ces derniers sont systématiquement montés au tour. D'une façon générale, les parois sont d'épaisseur irrégulière et variable, les fonds sont plats (fig. $19, n^{\circ} 1$ à 4 et 6 à 15 ) ou présentent un léger bombement pour de rares exemplaires (fig. 19, $\mathrm{n}^{\circ}$ ) ). La liaison fond-panse toujours marquée par une arête s'apparente au type Lisenboden (34)

Si le répertoire des formes reste limité, la morphologie des rebords apparaît plus différenciée. Le seul trait commun réside dans la quasi-absence de cols, panse et lèvre étant souvent confondus sans intermédiaire.

Le type le plus fréquent est la lèvre molle nettement déversée vers l'extérieur à profil externe arrondi. A l'intérieur de ce groupe plusieurs variantes sont identifiables. Le profil de la lèvre plus ou moins arrondi (fig. $15, n^{\circ} 1$ à 7,9 à $13,15,17$ et 18) peut être également angulaire (fig. $15, n^{\circ} 8,14$ et 15 ). Dans ce dernier cas, elle se présente comme plus courte.

Les décors ondés apparaissent systématiquement sur cette grande catégorie représentée par près des deux tiers des exemplaires recueillis. L'autre forme couramment attestée présente un col droit terminé par un simple bourrelet arrondi (fig. $16, \mathrm{n}^{\circ} 2,8,13$, et fig. $17, \mathrm{n}^{\circ} 3$, 5 et 6), plus rarement par une lèvre en flèche à extrémité supérieure plate (fig. $16, n^{\circ} 10$ et 12 ). La lèvre à bour- relet arrondi peut être parfois légèrement repliée vers l'extérieur (fig. 16, no 3,4 et 6 et fig. $17 \mathrm{n}^{\circ} 7$ ). C'est ce grand type qui domine sur les céramiques oxydantes (fig. 17, no 1,5 à 7 ).

Les autres formes nettement minoritaires sont les marlis horizontaux (fig. $16, \mathrm{n}^{\circ} 15$ et 16) ou obliques (fig. 16, n' 11,14 et 17), avec dans un cas deux anses juxtaposées (fig. 16, no 19), ou encore les lèvres aplaties rentrantes sur céramiques réductrices (fig. 17, $n^{\circ} 9$ ) et beiges ocrées (fig. 17, $\mathrm{n}^{\circ} 8$ ).

Les anses sont en ruban, larges de $4,5 \mathrm{~cm}$ à $6 \mathrm{~cm}$. Celles-ci peuvent être marquées par une gorge centrale et ont une face externe plate ou bombée, soulignée par deux côtes longitudinales. L'attache supérieure de ces anses semble se faire directement sur la lèvre en faisant corps avec elle. Elles restent peu écartées du profil de la panse ce qui devait rendre malaisée toute préhension. Seul un exemplaire fait figure d'exception (fig. 17, $\left.\mathrm{n}^{\circ} 10\right)$.

Les vases sont parfois munis d'un bec verseur (16 fragments soit $1,6 \%$ de la totalité du matériel découvert pour 1,3\% d'anses).

Ces derniers, pontés, tubulaires ou pincés se rencontrent de façon indiffërenciée sur plusieurs types de lèvres et présentent différents aspects. Un exemplaire (fig. 16, no 20) montre un tube bien distinct du col sans autre point d'attache que celui de sa fixation à la panse. Plus généralement le bec, que l'on peut décrire comme une tubulure oblique est fixé sur le haut de la panse, accolé à la lèvre, sur laquelle il peut être plus ou moins soudé, parfois même avec un apport d'argile pour renforcer le lien (fig. 17, $n^{\circ} 1$ ).

Enfin, parmi les formes rares plusieurs fragments appartiennent à un registre particulier. Il s'agit d'objets circulaires à surface plane délimitée par une arête vive, sans aucun rebord, et fixée sur un pied en corolle d'une hauteur comprise entre un et deux centimètres (fig. 19, $\mathrm{n}^{\circ} 16$ à 18). Faut-il les identifier comme dessous-deplats ou encore comme couvercles bien qu'aucun aménagement ne soit prévu pour leur préhension? Ces objets, absents à notre connaissance des répertoires typologiques des $X^{e}-X V^{e}$ siècles se rencontrent couramment sur plusieurs sites de plaine héraultais, datés par prospection des $\mathrm{X}^{\mathrm{e}}$-XII'e siècles (35).

53 tessons sont attribuables à plusieurs trompes d'appel. De couleur grise ou rouge ils présentent systématiquement un polissage longitudinal. Quatre fragments conservent un élément de suspension (fig. 20, $\mathrm{n}^{\circ} 1,2,3$ et 5). Il est maintenant manifeste que ces objets se rencontrent fréquemment sur des sites méridionaux des XIe-XII' siècles (36).

La principale caractéristique du matériel céramique du Rocher des Vierges est constituée par les décors. Ceux-ci pcuvent sc diviser en trois groupes particuliers: décor obtenu par ondes incisées, par polissage et, plus

(29) G. Bellan et L. Schneider, Un habitat du XI e siècle à Colombières-sur-Orb : Le site de Saucani, B. Soc. Archéol. et Hist. des Hauts Cantons de l'Hérault. 11, 1988, pp. 51-64.

(30) M. Dauzat, La motte du Mourrel..., op. cit..

(31) D. Baudreu et M. Dauzat, L'Habitat Médiéval de Saint-Andrieu (Fenouillet du Razès, Aude), Archéologie du Midi Médiéval, 3. 1985 , pp. $27-40$

(32) Le château et le village de Montaigut, Cahiers des Annales n 27, Archéologie du village déserté, p. 36.

(33) D. Garcia, O. Ginouvez, D. Orliac et L. Schneider, Inventaire archéologique de la Moyenne Vallée de l'Hérault, rapport dactylographié, Montpellier, 1987 (inédit).

(34) U. Lobbedey, Untersuchungen Mittelalterlicher Keramik vornemlich aus Sudwest-Deutschland, Berlin, 1968.

(35) C'est le cas notamment des sites de Saint-Julien-d'Avizas à Saint-Félix-de-Lodez et de Mazers à Fontes.

(36) L'on se reportera pour comparaisons aux trompes d'appel de Cucuron, voir E. Faure-Boucharlat, M. Colardelle, M. Fixot et J.P. Pelletier, Eléments comparatifs de la production céramique du XI' siècle dans le bassin rhodanien, La céramique médiévale en Méditerranée Occidentale, éditions du C.N.R.S., p. 435, planche 4, no 2 , mais aussi M. Dauzat, La motte du Mourrel..., op. cit., p. 39, planche 17, n B3. 238., M. Dauzat, D. Baudreu, op. cit., p. 36, fig. 8, nos 42 et 43 , A. Kauffmann, J.P. Pelletier, J. et Y. Rigoir, Les céramiques de l'antiquité tardive au XI' siècle dans les fouilles de la place Jean-Jaurès à Apt, Archéologie du Midi Médiéval, 5,1987, p. 83 , fig. $16, \mathrm{n}^{\circ} 98$. 

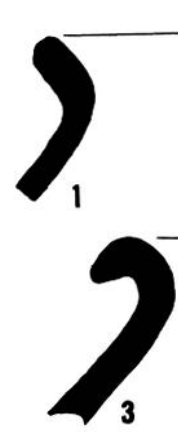

4

3
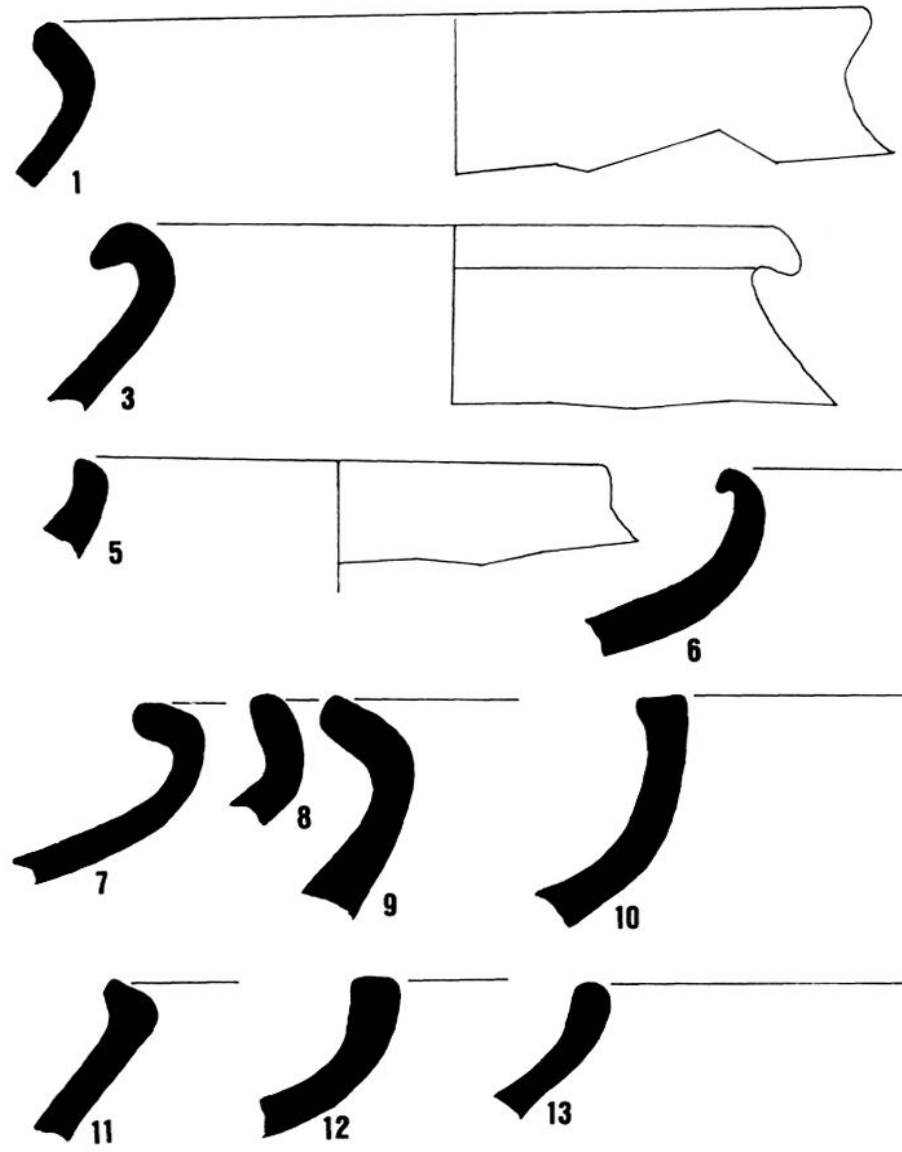
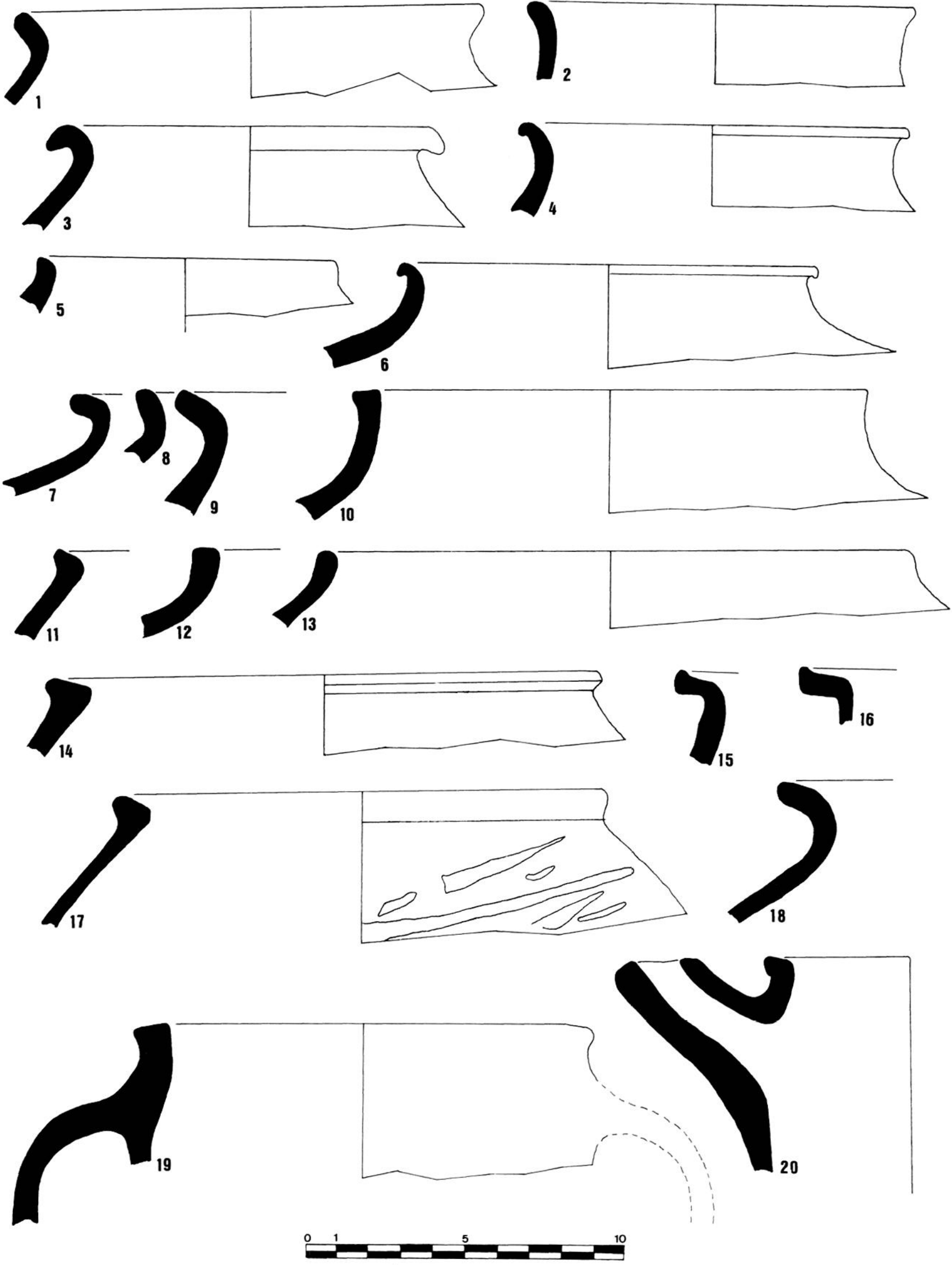

Fig. 16: Céramiques réductrices non polies, $n^{\circ} 1$ à 16 et 18 à 20 , céramique réductrice polie, $n^{\circ} 17$. 

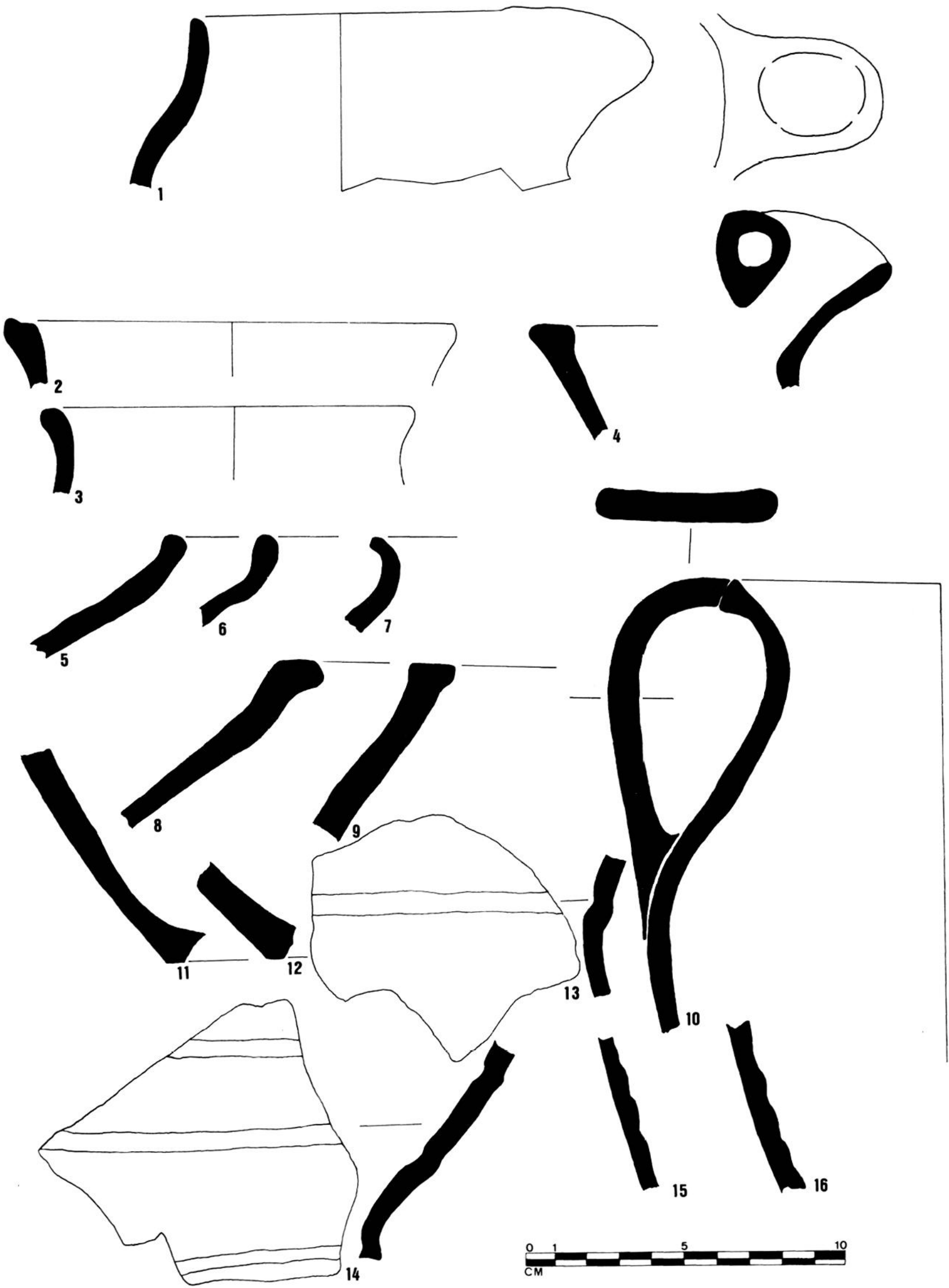

Fig. 17: Céramiques réductrices non polies, $\mathrm{n}^{\circ} 2$ à 4,9 et 10,13 et 14 ; céramiques fines oxydantes et polics $\mathrm{n}^{\circ} 6,15$ ct 16 ; céramiques oxydantes non polies, $n^{\circ} 1,5$ et 7 ; céramiques à pâte beige/ocrée polies $n^{\circ} 8,11$ et 12 . 

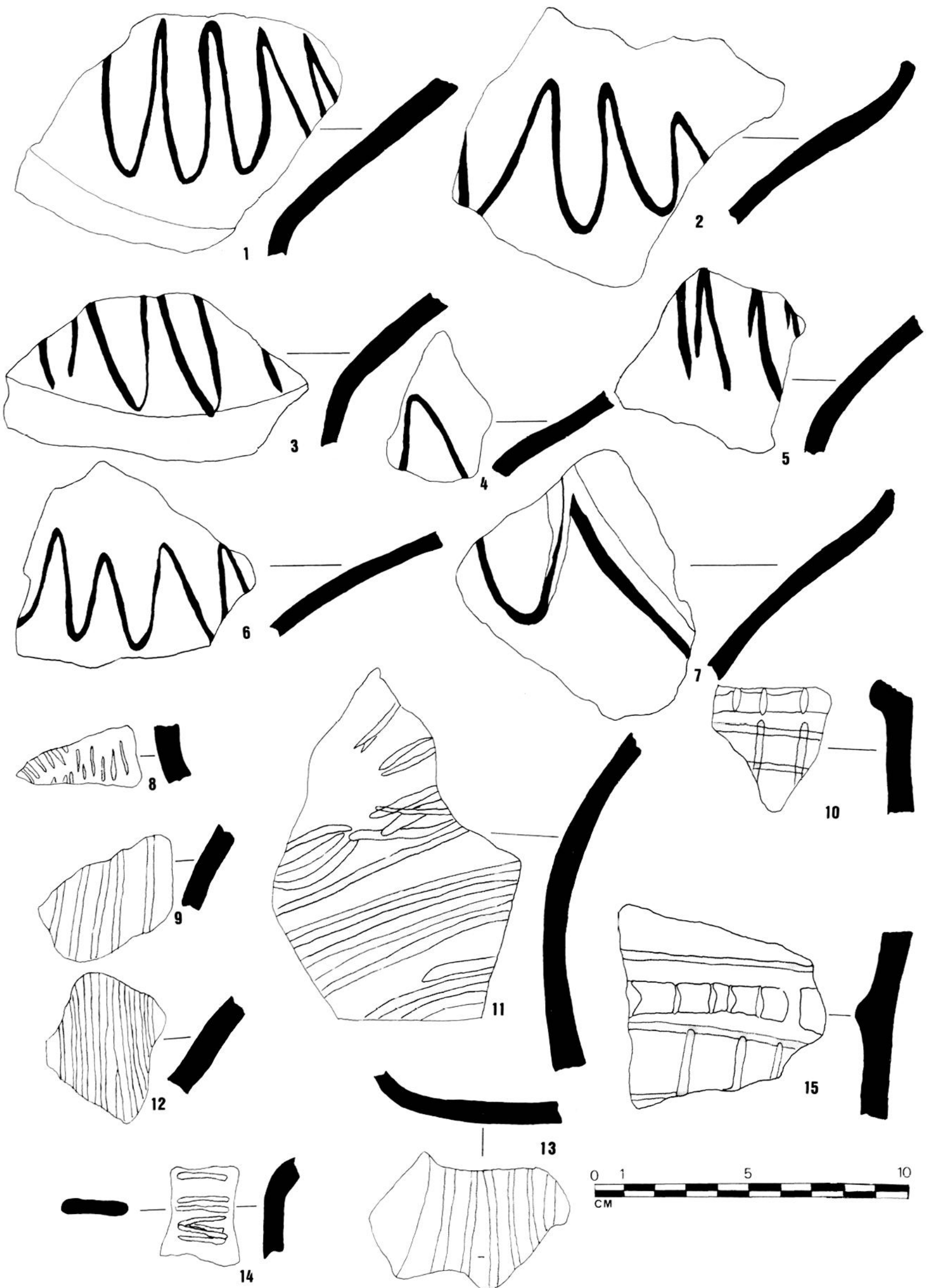

13

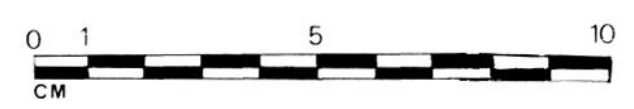

Fig. 18 : Céramiques réductrices non polies, $\mathrm{n}^{\circ} 1$ à 7 ; céramiques réductrices polies, $\mathrm{n}^{\circ} 8$ et 9,11 à 13 ; céramiques oxydantes polies, $n^{\circ} 14$ et 15 ; céramique oxydante fine et polie, $n^{\circ} 14$. 
marginalement, par guillochis, cordon pincé incisé et gorge réalisée par pression du doigt lors du tournage.

Le décor ondé demeure toujours associé à des céramiques réductrices non polies présentant des lèvres déversées, arrondies ou plus rarement angulaires. Il ne se rencontre que dans les parties hautes des vases. L'onde peut être plus ou moins incisée, plus ou moins sécante et régulière, parfois double. C'est en fait la variabilité qui reste la rc̀glc (fig. $15, \mathrm{n}^{\circ} 1,2,4,6,8,14$ et 16 et fig. $18, n^{\circ} 1$ à 7 ).

Ce décor est attesté sur plusieurs sites Héraultais comme ceux de Gorjan (Clermont-l'Hęrault) (37), du Cimetière Vieux (Nébian) (38) ou encore de SaintPierre-de-Pabiran (Montagnac) (39) et de Saucani (Colombières-sur-Orb) (40). Il est également signalé sur d'autres sites languedociens : à Saint-Andrieu (Fenouillet-du-Razès) (41), à Saint-Martin (Siran) (42), sur l'oppidum de Lombren (Vénéjan) (43), mais aussi à la grotte de la Fourbine dans les Bouches-du-Rhône, identifié sous la forme de chevrons et de méandres incisés (44), enfín dans les niveaux médiévaux des. fouilles de la Bourse à Marseille (45).

En`soi, le décor ondé ne peut servir de flécheur chronologique. Les prospections effectuées dans la moyenne vallée de l'Hérault, sur plusieurs sites de plaine, l'attestent sur des céramiques grises jusqu'aux XII ${ }_{-}$ $X I I I^{c}$ siècles (46). Les fouilles entreprises à Cabrières sur le site de la Cisterne révèlent son existence sur des céramiques oxydantes du bas Moyen Age (47). Cependant, sa fréquence plus importante à Saint-Saturnin dépasse le simple fait marginal et constitue la caractéristique essentielle de cette série.

Le deuxième type de décor rencontré est réalisé par polissage (48), aussi bien sur cuisson oxydante que sur cuisson réductrice. Les décors polis sur céramique commune sont connus dès le premier siècle après J.-C. à Lattes (49) et sont encore attestés au Ve siècle à la grotte de l'Hortus (50), et à l'oppidum de Lombren (51). Ils sont enfin fréquemment associés à des céramiques du $\mathrm{XI}^{\mathrm{e}}$ siècle à Cucuron (52) et Charavines (53). Il est généralement admis que ce décor lorsqu'il est constitué de bandes parallèles ou enchevêtrées, représenté jusqu'au $\mathrm{XI}^{\circ}$ siècle, disparaît ensuite. Les travaux réalisés par Michel Dauzat, notamment sur la motte de Couges (54), doivent cependant nuancer ce propos puisque l'auteur les rencontre sur des marmites des XIVe-XVe siècles.

Quelques tessons du dépotoir de Saint-Saturnin présentent nettement un enchevêtrement de plusieurs bandes (fig. 18, $\mathrm{n}^{\circ} 8,9,11,12$, et 14 et fig. $16, \mathrm{n}^{\circ} 17$ ), ou un quadrillage (fig. 18, no 10 et 15) (55), semblables aux séries provençales et alpines.

C'est avant tout le traitement de surface par polissage couvrant, plus que le polissage par bandes et/ou croisées, qui caractérise notre échantillonage. Certains fragments de fonds sont d'ailleurs également polis (fig. 18, $\mathrm{n}^{\circ} 13$ ). Cette observation tient aussi au fait qu'il est parfois difficile d'identifier ce traitement à l'œil nu. Lorsque les bandes forment un treillis de lignes entrecroisées très serrées, elles nous sont révélées dans bien des cas par le seul toucher.

Proportionnellement, ce décor est attesté sur $67,52 \%$ des céramiques à pâte rouge, contre $18 \%$ pour celles à pâte grise et sur tous les fragments à pâte beige ocrée.

Le troisième groupe est composé d'exemples marginaux non représentatifs de la série étudiée $-0,99 \%$ du total des décors. Il s'agit de guillochis (fig. 15, n० 9), ou encore de cordons pincés incisés sur céramique oxydan-

(37) O. Ginouvez et L. Schneider, Témoins médiévaux sur le site antique à Clermont-l'Hérault, B. du G.R.E. Clermontais, n 2-3, 1986, pp. 26-32.

(38) O. Ginouvcz ct L. Schneider, Nébian, Le cimetière vieux (prépublication du colloque de 1989 à Aix-en-Provence sur la topographie religieuse) (à paraître).

(39) M. Feugère et D. Rouquette, Le site antique et médiéval de Saint-Pierre de Pabiran à Montagnac (Hérault), Eludes sur l'Hérault, $n^{\circ} 3,1985$, pp. 3-9.

(40) G. Bellan et L. Schneider, op. cit.

(41) D. Baudreu et M. Dauzat, op. cit.

(42) G. Bordenave, H. Martinole et T. Martin, Saint-Martin, site paléo-chrétien et pré-roman, $R$. Archéol. de Narbonnaise, 3, 1970, pp. 141-172.

(43) J. Charmasson, L'oppidum Bas-Rhodanien de Lombren (Gard), L'habitat paléochrétien, Cah. Rhodaniens, IX, 1962, pp. 64-102.

(44) G. Conges, M. Bonifay, J.P. Brun et M. Pasqualini, Un dépotoir de la fin de l'antiquité dans la grotte de la Fourbine, SaintMartin-de-Crau (B.-du-R.), R. Archéol. de Narbonnaise, XVI, 1983, pp. 347-361.

(45) M. Bonifay et J.P. Pelletier, Céramiques de l'antiquité tardive et du Haut Moyen Age à Marseille, R. Archéol de Narbonnaise, tome XVI, 1983, pp. 285-346, et notamment p. 343, fig. 42, n 338.

(46) Prospections réalisées sur le site castral de Vailhan (34) et de Gorjan à Clermont-l'Hérault.

(47) O. Ginouvez et L. Schneider, La recherche archéologique médiévale dans la Moyenne Vallée de l'Hérault, Arch. en Lang., 1986 (3), pp. 55-62.

(48) Le polissage est une technique de traitement de surface qui correspond à des critères bien précis. Ceux-ci ont déjà été énoncés par D. Baudreu et M. Dauzat, L'habitat médiéval de Saint-Andrieu..., op. cit., p. 29, n'11, qu'il nous soit permis de les rappeler dans cette présente note.

Le polissage est le résulat du passage d'un corps dur et lisse sur une poterie en cours de séchage, ce qui a pour effet d'étaler en surface les particules d'argile et de créer un effet de brillance plus ou moins prononcé. Cf. Atanica 5 , Les civilisations néolithiques du Midi de la France, Actes du Colloque de Narbonne, 15-17 février 1979, p. 52 et H. Balfet, M.F. Fauvet-Berlhelot et S. Monzon, Pour la normalisation de la description des poteries, C.N.R.S., 1983, p. 87. Cette technique se différencie du lissage qui est le résultat du passage d'un corps mou (chiffon, éponge, feuille ou main mouillée) sur une poterie à l'état humide. L'aspect de la pièce ainsi traitée est uni et mat iCf. H. Balfet. op. cit.. p. 85).

(49) Des décors polis constitués de lignes ondulées ont été observés sur des céramiques réductrices du jer siècle ap. J.-C. découvertes en 1988 dans le comblement d'un puits sur le site de Lattes (34) (renseignements oraux Michel Py).

(50) G. Démians d'Archimbaud, Le matériel paléochrétien de la grotte de l'Hortus, El. quaternaires I. 1972. pp. 635-657.

(51) J. Charmasson, op. cit.

(52) M. Fixot et J.P. Pelletier, Une forme originale de fortification provençale: Le Castellas de Cucuron (Vaucluse), Archéologie Médiévale, XIII, 1983, pp. 89-143.

(53) R. et M. Colardelle, L'habitat médiéval immergé de Colletières à Charavines (Isère). Premier bilan des fouilles, Archéologie Médiévale, X, 1980, pp. 192-194.

(54) M. Dauzat, Une motte castrale du Razès, Couges (Aude), Archéologie du Midi Médiéval, 1, 1983, pp. 23-36.

(55) Les rares exemples de quadrillages sont effectués sur céramique oxydante à paroie épaisse et s'associent à un décor à cordon pincé incisé. 

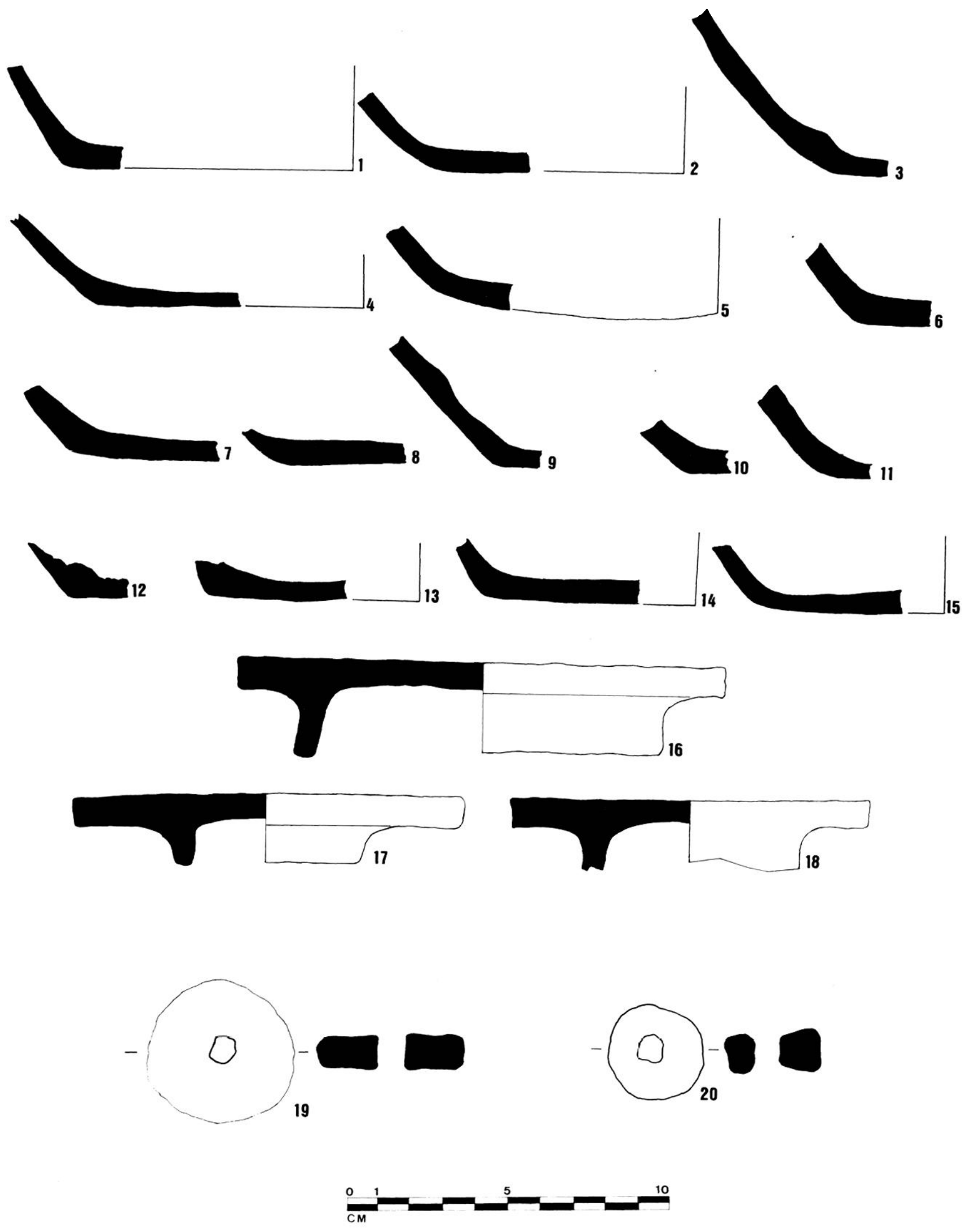

Fig. 19: Céramiques réductrices non polies, $n^{\circ} 2$ à 15,16 à 18 ; céramique réductrice polie, $\mathrm{n}^{\circ} 1$; céramiques oxydantes fines, $\mathrm{n}^{\circ} 12$ à 15 ; fusaïoles, $n^{\circ} 19$ et 20. 
te (fig. 18 , no 10 et 15 ). Enfin, quelques éléments présentent une série de gorges obtenues par pression d'un doigt lors du tournage (fig. $17, n^{\circ} 13$ et 14).

\subsubsection{Problèmes de chronologie et datation.}

La datation de ces documents demeure un problème délicat. Localement, les affinités ou les disparités typologiques avec un matériel fragmenté retrouvé presque exclusivement à partir de prospections, sur des sites datés par leur seul contexte, rendent difficile toute comparaison.

Actuellement, le mobilier céramique de SaintSaturnin s'oppose nettement à celui découvert dans les niveaux bas médiévaux des fouilles de Cabrières (56).

Quelques éléments précis - décors ondés, céramique ocrée, polissage - sont attestés sur des sites nouvellement découverts et encore saisis dans une chronologie très large - VII ${ }^{c}$-XII ${ }^{e}$ siècles - (57).

Les données strictement locales ne permettent pas d'étayer des datations plus précises.

Il est manifeste cependant que notre série présente dans ses caractères généraux des affinités avec les céramiques de plusieurs sites languedociens et même provençaux. Typologiquement, le meilleur critère de comparaison reste celui des lèvres. Le type le plus fréquent à Saint-Saturnin, la lèvre nettement déversée vers l'extérieur, trouve de nombreuses équivalences à SaintAndrieu (58), Molleville et Laurac (59) dans l'Aude, sur des sites datés des $\mathrm{XI}^{\mathrm{e}}$-XII ${ }^{\mathrm{e}}$ siècles, mais aussi à Cucuron (60) et dans les niveaux médiévaux des fouilles de la Bourse à Marseille (61). Pour ces deux derniers exemples la chronologie proposée est le XI' siècle.

Les lèvres courtes terminées par un simple bourrelet sont bien connues à Pataran (62) dans des phases d'occupation des $\mathrm{X}^{\mathrm{e}}$-XI $\mathrm{I}^{\mathrm{e}}$ siècles et, à Saint-Symphorien dans les couches IV antérieures à l'an Mil (63).

En définitive, malgré quelques analogies frappantes avec le matériel provençal, le mobilier du Rocher des Vierges doit être saisi dans une perspective régionale. Par delà les affinités, des absences sont à signaler, des traitements différents à noter. En premier lieu, on observera l'inexistence de lèvres en bandeaux pourtant fréquemment associées aux lèvres déversées à Cucuron (64), dans la vallée du Rhône (65). Les fonds bombés sont relativement peu nombreux, le décor à la roulette est absent. Le polissage prend plus souvent l'aspect d'un traitement de surface et peut affecter les fonds euxmêmes. Enfin, le décor ondé apparaît comme le caractère le plus spécifique de cette production.

La présence de céramique beige ocrée polie, d'un type oxydant de céramique fine à lèvres courtes et arrondies nous conduit à proposer une datation qui couvrirait les $\mathrm{X}^{\mathrm{e}}-\mathrm{XI}^{\mathrm{e}}$ siècles. Celle-ci ne peut être étayée par les éléments stratigraphiques, encore moins par les monnaies dont l'absence est à regretter. Elle trouve tout de même sa justification dans les traits communs qu'elle présente avec un faciès languedocien et provençal - polissages, forme des lèvres, répartition des pourcentages entre céramiques oxydantes et réductrices, présence exclusive de formes fermées - mais surtout avec des comparaisons microrégionales ; céramiques beiges ocrées et décors ondés sont parfois associées à des céramiques du haut Moyen Age - céramique réductrice à aspect bleuté, parfois craquelé.

Enfin, le dépotoir lui-même se situe dans la première phase d'occupation médiévale du site. Celle-ci comme le suggère l'analyse des documents écrits ne saurait être antérieure au $\mathrm{X}^{c}$ siècle et viendrait ainsi corroborer les datations proposées pour la céramique.

En définitive, la chronologie du matériel de SaintSaturnin, cernée dans une perspective assez large, comporte de nombreuses lacunes puisqu'elle reste fondée avant tout sur une analyse typologique empirique. Elle permet toutefois d'établir des hypothèses de travail et de poser les premiers jalons de datation pour l'étude encore immature de la céramique médiévale en Languedoc central.

\subsection{Autre mobilier.}

Le mobilier métallique est minoritaire. Outre 61 fragments d'objets en fer, indéterminables pour cause de conservation hormis la partie inférieure d'une clef et un petit marteau pied de biche (fig. $21, n^{\circ} 1$ ), on notera la découverte d'une perle biconique et d'une épingle courte, en bronze (fig. $21, \mathrm{n}^{\circ} 2$ et 3 ).

Les éléments de verres sont quasi-absents si ce n'est l'existence d'une perle en pâte bleutée (fig. $21, n^{\circ} 4$ ).

On note enfin la présence de 13 fusaioles, dont deux taillées dans des fragments de tuiles et onze dans des tessons de céramique oxydante à pâte épaisse (fig. 19, no 19 et 20).

\subsection{La faune}

\subsubsection{Comptages et analyse}

Les restes de faune, provenant du «dépotoir » ont également fait l'objet d'une étude qui, bien qu'encore incomplète à l'heure actuelle, permet de présenter des résultats essentiellement quantitatifs puisque nous considérons avoir là un ensemble complet.

Les restes osseux, particulièrement importants, ont tout d'abord fait l'objet d'un nettoyage attentif. Ce premier contact avec le matériel nous a permis d'avoir une première vue d'ensemble qui a pu être confirmée par l'examen de chacune des pièces osseuses au sein de leur couche propre. Nous avons ainsi repéré les trois espèces principales que sont le bœuf, le porc et le mouton (peutêtre la chèvre aussi mais dont la présence n'a pas été sûrement attestée, au contraire du mouton).

D'autre part, la dominance de restes demeurés in-

(56) O. Ginouvez et L. Schneider, La recherche..., op. cit.

(57) Ces sites correspondent à des nécropoles isolées, comme celle des Carlencas à Fontes (34) ou à des habitats de l'antiquité tardive et du haut Moyen Age : Les Arénasses au Pouget (34), Saint-Etienne-de-Trignan à Neffiès (34) et/ou du haut Moyen Age: Les Cazaux au Pouget (34).

(58) D. Baudreu et M. Dauzat, op. cit..

(59) M. Dauzat, La motte du Mourrel..., op. cit.

(60) M. Fixot et J.P. Pelletier, Une forme originale..., op. cit.

(61) M. Bonifay et J.P. Pelletier, op. cit.

(62) E. Roth, Les fouilles de Pataran, Ec. antique de Nimes, 6-7, 1971/1972, pp. 73-94.

(63) I. Barbier, M. Fixot et J.P. Pelletier, Encore le prieuré de Saint-Symphorien de Buoux, Provence historique, XXXIII Fasc. 133, sept. 1983, pp. 285-336.

(64) M. Fixot et J.P. Pelletier, une forme originale..., op. cit..

(65) J.F. Reynaud, M. Colardelle, M.C. Bailly-Maître, E. Boucharlat, M. Clermont, B. Mandy et B. Manipoud, Etude d'une céramique régionale: Les vases à fond marqué du XIc siècle dans la région Rhône-Alpes, Archéologie Médiévale, V, 1975, pp. $245-285$.

E. Faure-Boucharlat, M. Colardelle, M. Fixot et J.P. Pelletier, op. cit.. 

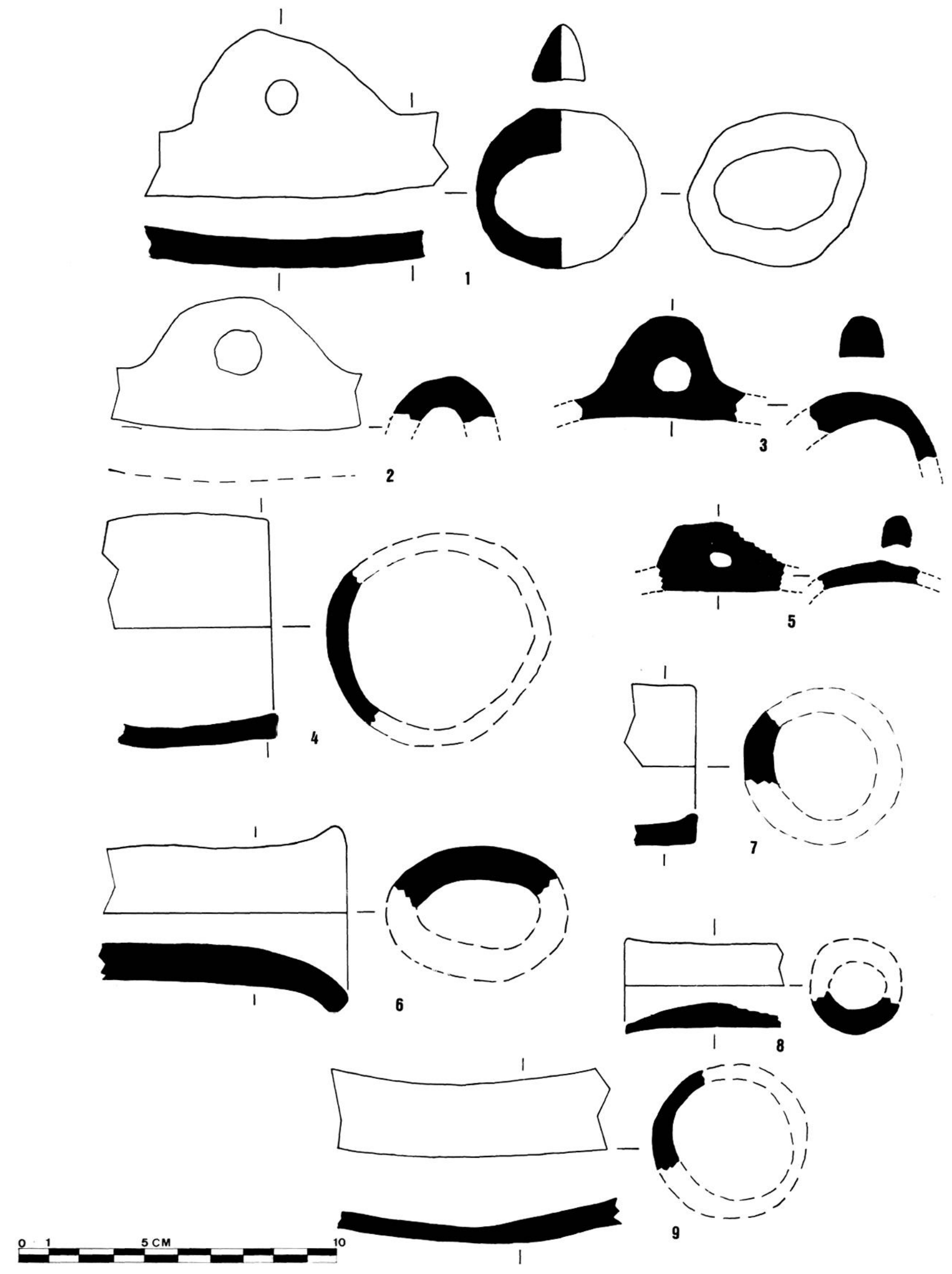

Fig. 20: Trompes d'appel, cuisson réductrice, $n^{\circ} 3$; cuisson oxydante $n^{\circ} 1,2,4$ à 9 . 


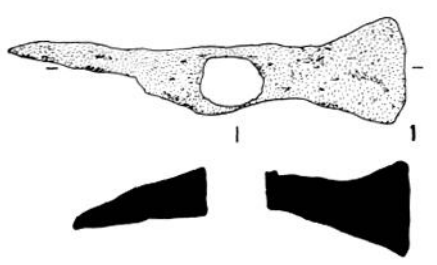

-0.1

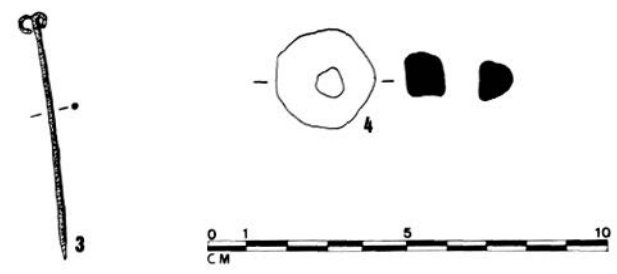

Fig. 21: 1. Marteau pied de biche.

2. Perle biconique.

3. Aiguille courte.

4. Perle en pâte bleutée.

déterminés tels que des esquilles d'os et des côtes et vertèbres fragmentées s'est trouvée vérifiée lors du dénombrement des pièces.

Nous avons pu répertorier un total de 4000 fragments indéterminés représentant $54 \%$ de l'ensemble du matériel et répartis comme suit :

Couche $1001: 51,4 \%$

Couche 1002:53,1\%

Couche $1003: 45,2 \%$

Couche $1004: 40,2 \%$

Couche $1006: 64,4 \%$

De même que pour le pourcentage global, les restes indéterminés représentent pratiquement pour chaque couche la moitié du matériel. La grande proportion de côtes et d'esquilles au sein de chaque couche se matérialise également par des pourcentages importants.

Couche 1001 : côtes : $24,6 \%$ esquilles : $26,3 \%$

Couche 1002 : côtes : $51 \%$ esquilles : $28 \%$

Couche 1003 : côtes : $48,2 \%$ esquilles : $36,6 \%$

Couche 1004 : côtes : $59 \%$ esquilles : $26,4 \%$

\section{Couche 1006 : côtes $52, \%$}

esquilles : $26,4 \%$

Remarque : Les côtes et vertèbres de bœufs ont été isolées. Nous considèrerons donc que ces résultats correspondent à des restes de moutons et de porcs.

Cette majorité d'indéterminés s'explique par l'état particulièrement fragmenté de ces pièces.

En ce qui concerne les restes osseux déterminés, ils représentent un total de 3410 pièces soit $46 \%$ de l'ensemble du matériel.

Ont été reconnus, pour les bovidés le bœuf domestique, pour les ovicaprinés le mouton (la présence de chèvre n'étant pas exclue), pour les suidés le porc, pour les lagomorphes le lapin et le lièvre, pour les carnivores la présence d'un chat et de coprolithes de chien mais aussi des restes de volailles de basse-cour et enfin des restes de poissons très peu nombreux et qui n'ont pu être déterminés.

Nous avons rassemblé l'ensemble des résultats dans un tableau tenant compte des différentes couches: un diagramme basé sur les pourcentages de présence des espèces permet de visualiser ces résultats (fig. 22 et 23 ).

On s’aperçoit très vite que les couches 1001 et 1003 sont les plus riches. Rappelons que ce sont également ces dernières qui ont livré le matériel céramique le plus abondant; elles feront donc l'objet d'une étude plus détaillée (fig. 24 et 25 ).
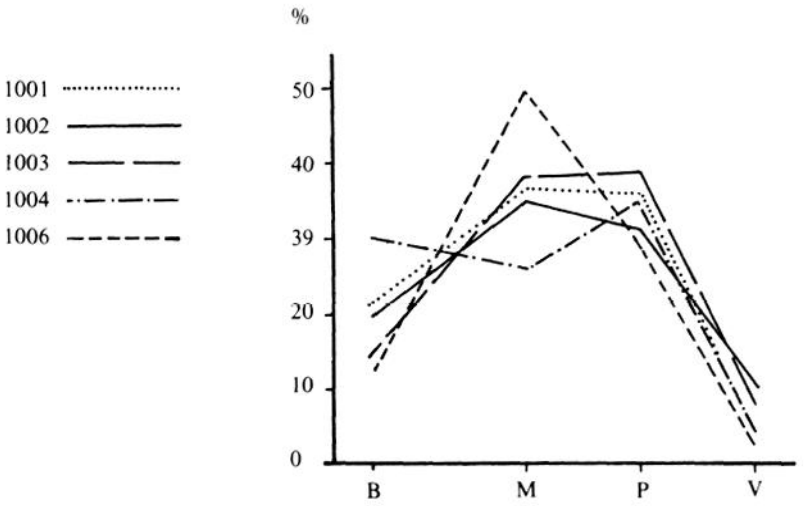

Fig. 23 : Pourcentage de la présence de chaque espèce au sein de chaque couche.

\begin{tabular}{|l|c|r|r|r|r|r|r|r|r|r|r|r|r|r|r|r|r|}
\hline & 1001 & & & 1002 & & & 1003 & & & 1004 & & & 1006 & & & Total & \\
\hline & & & & & & & & & & & & & & & & & \\
\hline & NF & $\%$ & NMI & NF & $\%$ & NMI & NF & $\%$ & NMI & NF & $\%$ & NMI & NF & $\%$ & NMI & NMI & \\
\hline & & & & & & & & & & & & & & & & & \\
\hline Bœuf & 233 & 22 & 4 & 45 & 21 & 4 & 247 & 15 & 5 & 68 & 32 & 2 & 39 & 14 & 2 & 17 & \\
\hline Mouton & 393 & 37 & 30 & 79 & 36 & 9 & 602 & 37 & 32 & 57 & 27 & 9 & 136 & 50 & 9 & 89 & \\
\hline & & & & & & & & & & & & & & & & & \\
\hline Porc & 382 & 36 & 24 & 71 & 33 & 8 & 620 & 38 & 33 & 77 & 36 & 10 & 80 & 29 & 5 & 80 & \\
\hline & & & & & & & & & & & & & & & & & \\
\hline Lagomorphe & 5 & 0,5 & 2 & 1 & 0,5 & 1 & 32 & 2 & $?$ & 1 & 0,5 & 1 & 5 & 1,8 & $?$ & & \\
\hline & & & & & & & & & & & & & & & & & \\
\hline Chat & 1 & 0,1 & 1 & & & & & & & & & & 1 & 0,4 & 1 & & \\
\hline & & & & & & & & & & & & & & & & & \\
\hline Poisson & 6 & 0,6 & $?$ & 4 & 1,8 & $?$ & 5 & 0,2 & $?$ & & & & 4 & 1,4 & $?$ & & \\
\hline & & & & & & & & & & & & & & & & & \\
\hline Volaille & 54 & 5 & $?$ & 18 & 8,3 & $?$ & 121 & 7,4 & $?$ & 12 & 5,6 & $?$ & 10 & 3,6 & $?$ & & \\
\hline & & & & & & & & & & & & & & & & & \\
\hline TOTAL & 1074 & & 61 & 218 & & 22 & 1628 & & 70 & 215 & & 21 & 275 & & 17 & & 3410 \\
\hline
\end{tabular}

Fig. 22 : Répartition des restes osseux sur l'ensemble des couches. 


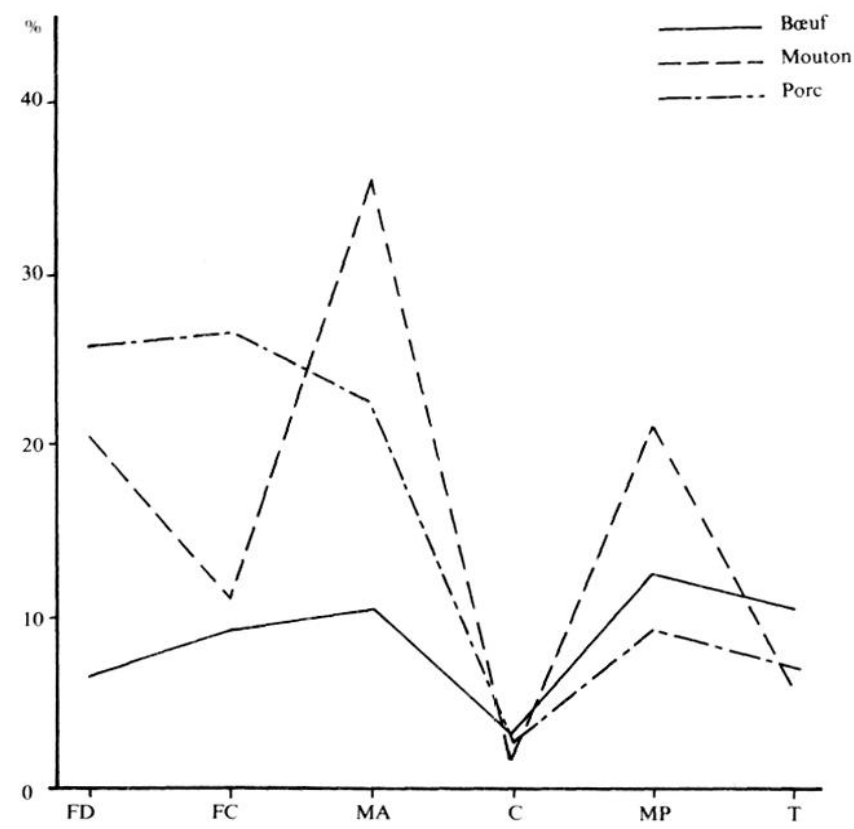

Fig. 24 : Répartition des restes osseux, U.S. 1001.

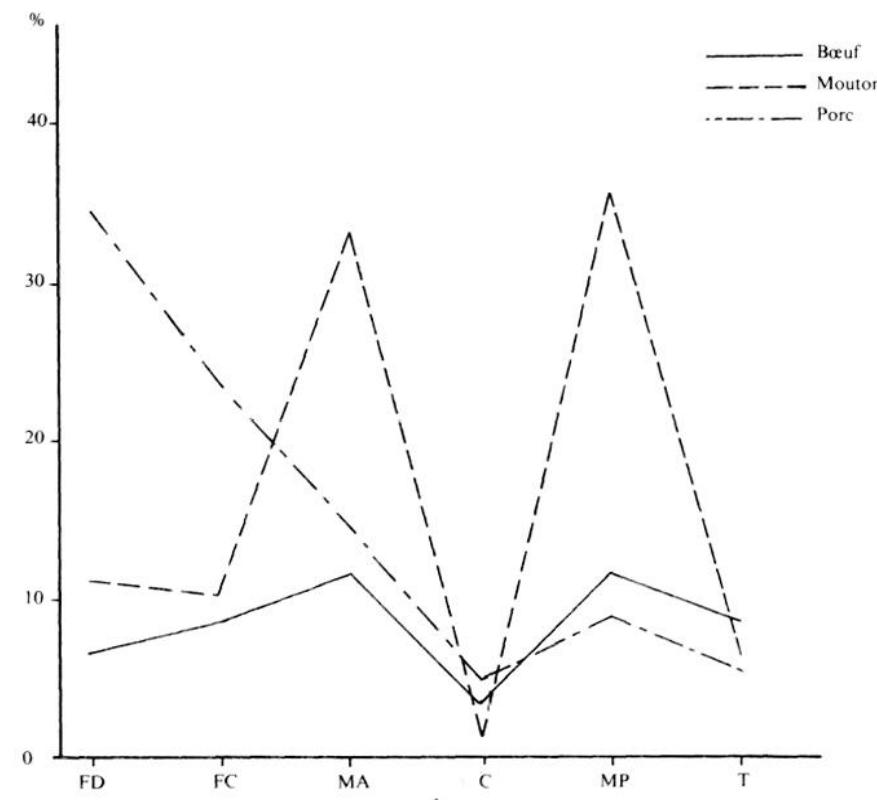

Fig. 25 : Répartition des restes osseux, U.S. 1003.

Les pourcentages de présence des animaux sont du même type. On voit sur le diagramme qu'ils s'associent de cette manière à la couche 1002 qui comporte pourtant une quantité de vestiges biens moins importante.

Suite à l'étude de la stratigraphie, nous pourrions émettre l'hypothèse que ces trois couches forment un ensemble distinct localisé dans la partie nord par opposition à l'extrémité sud de la pièce-dépotoir où s'étagent les couches 1004 à 1006. Ne tenant pas compte de 1005 qui correspond à une structure plus qu'à un lot de matériel, nous constatons que 1004 et 1006 different par leurs proportions d'animaux. Nous n'en tirerons pas de conclusions trop hâtives puisque cet "ensemble sud" n'a pu être clairement défini à cause, d'une part, des intrusions successives dues à des fouilles clandestines qui auraient endommagé ces niveaux et, d'autre part, à l'hypothèse qui consisterait à penser que la couche 1004 résulterait d'un glissement de terrain qui aurait fait se mélanger en 1004 une partie des couches 1001 et 1003 .

Sachant que 1001 et 1003 sont constituées des mêmes animaux et dans les mêmes proportions, nous avons voulu voir comment se répartissent les fragments osseux par rapport à leur situation anatomique et dans quelles mesures certaines parties de l'animal ont pu être consommées en priorité.

Nous avons donc pris en considération les trois espèces représentatives du gisement à savoir le bœuf, le mouton et le porc.

Les résultats sont présentés sous forme de diagrammes et mettent en rapport les pourcentages des pièces osseuses par animal et par couche. Pour cela nous avons sélectionné les parties suivantes:

FD : fragments dentaires (mandibules, maxillaires, dents isolées).

FC : fragments crâniens (FD exclus). ulna).

MA : membre antérieur (scapula, humérus, radius,

$C$ : carpe et métacarpe (main) fibula)

MP : membre postérieur (coxal, fémur, tibia,

$$
\mathrm{T} \text { : tarse et métatarse (pied). }
$$

\section{Mouton (fig. 26)}

Les membres semblent avoir été consommés en priorité, par contre, leurs extrémités sont peu représentées et ne semblent pas avoir été découpées. Les fragments crâniens et dentaires sont assez nombreux. La tête et la cervelle ont été consommées; en effet les crânes ont été coupés longitudinalement et souvent au niveau de la symphyse pour les mandibules. Nous n'avons pas observé de traces de décarnisation du crâne ni de la face. Actuellement, on trouve de ces demi-têtes d'agneau à l'étal du boucher.

Les cornes, lorsqu'elles étaient présentes, étaient coupées et la tête préparée en vue de la consommation de la langue, de la joue et de la cervelle.

En dehors de la tête, du cou, des épaules et des gigots, le boucher préparait des côtes, échines ou plats de côtes (selon l'appellation actuelle) qui étaient cuites à même le feu : certaines extrémités de côtes sont brûlées et les vertèbres sont fendues soit longitudinalement, soit de part et d'autre du corps, en particulier pour les thoraciques mais aussi sur les lombaires.

Remarque: les proportions de côtes et vertèbres n'apparaissent pas dans les diagrammes puisqu'elles n'ont pas été triées.

Pour la découpe des membres, on se reportera à la figure correspondante.

L'utilisation des mains et des pieds n'a pu être constatée, faute de restes. Ceci pourrait s'expliquer par le fait qu'ils sont constitués d'os de petite taille ayant pu échapper à la fouille.

Peu de chevilles osseuses de cornes: elles n'ont pas été travaillées mais portent les traces du couperet ou du hachoir qui les a séparées de la boîte crânienne. Il n'y a donc aucune trace d'une industrie de la corne.

Porc (fig. 26).

En ce qui concerne le porc, et bien que les restes des membres antérieurs et postérieurs soient toujours supérieurs à ceux des carpes et tarses, ce sont les fragments dentaires et crâniens qui dominent largement, totalisant $52,4 \%$ en 1001 et $58,5 \%$ en 1003.

Là encore, aucune trace de découpe au niveau des métapodes et os carpiens et tarsiens ne permet d'affirmer que ces parties aient été préparées d'une quelconque manière.

Pour la patte avant, il semble que la coupure du tendon très résistant reliant l'apophyse coracoïde à l'humérus ait provoqué une cassure de l'omoplate au-dessus de l'articulation. L'humérus et le radius ont reçu deux coups séparant les extrémités articulaires des diaphyses. Les ulnas sont souvent restées entières.

La colonne vertébrale a été sectionnée de façon à détacher le train de côtes, soit qu'on l'ait coupée en deux longitudinalement, soit que les coups aient été portés de part et d'autre des apophyses vertébrales. Les côtes elles-mêmes, retrouvées très fragmentées et portant de nombreuses stries sont restées dans le lot des côtes de mouton-porc.

Au niveau du membre postérieur, l'aile iliaque a été tronquée (détachement du coxal au couperet ?) puis le fémur a été détaché de la cavité cotyloüde. 

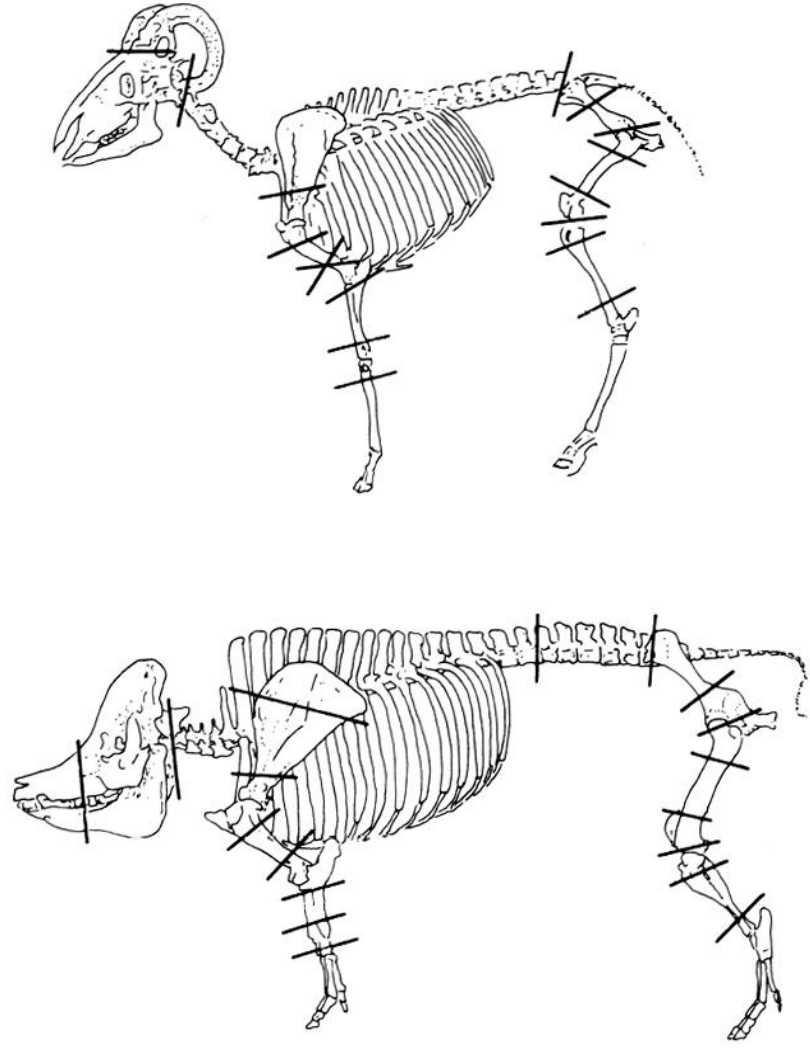

Fig. 26: Traces de découpe sur le mouton et le porc.

Des extrémités distales de fémur ont également été retrouvées isolées, certaines portant sur les condyles la marque de la séparation fémur-tibia. Le tibia a souvent été cassé en deux coups, découpe que l'on trouve aussi sur les fibulas.

En ce qui concerne la tête, les résultats semblent montrer qu'elle représentait un morceau de choix. De nos jours, elle est toujours utilisée et se retrouve chez le boucher soit en morceaux (museau), soit sous forme de pâté, soit tranchée en deux comme pour le mouton (plus rarement).

Le schéma de découpe ressemble à celui du mouton. La tête, après avoir été séparée du reste du corps par un coup atteignant souvent les condyles occipitaux ou moins souvent la partie crâniale de l'atlas, est fendue longitudinalement, les mandibules étant séparées au niveau de la symphyse.

D'autre part, certaines demi-têtes pouvaient encore être débitées en séparant directement le museau: on a retrouvé quatre fragments de mandibules qui n'avaient pas été séparées à la symphyse mais cassées entre la quatrième prémolaire et la première molaire.

Ces constatations laissent supposer que la cervelle était consommée de même que les autres parties de la tête.

Enfin la découpe des membres atteste, comme chez le mouton, de la consommation importante de porcs (se reporter aux figures de découpe).

Beuf.

Les résultats sont difficilement interprétables car la présence du bœuf est peu importante par rapport à celle du couple mouton-porc. Celui-ci reste majoritaire dans chacune des couches.

On constate une fois de plus que ce sont les os des membres qui sont les plus nombreux mais ils ne portent pas de marques caractéristiques. Les fragments de côtes montrent les cassures, stries et coups portés par le boucher lors de la préparation de l'animal.

Les fragments crâniens sont assez importants mais aussi très fragmentés.

On remarquera la présence d'un fragment proximal de radius (partie médiale) fendu dans sa hauteur et deux fragments de bassin sciés (?) de part et d'autre de l'acétabulum.

Un fragment de coxal gauche (ischion) porte aussi les traces de découpe en particulier celle d'une percussion au niveau de la suture du bassin. D'autres fragments encore ont pu être sciés : ils en portent les traces au niveau de l'os iliaque.

Enfin, la présence d'une ulna droite dont l'olécrâne a été cassé lors de la désarticulation laisse supposer que le membre antérieur a été découpé au niveau du coude.

Les phalanges et os du tarse sont nombreux mais ne présentent pas de traces significatives.

Les vertèbres ont elles aussi été fendues longitudinalement, surtout les lombaires, alors que les cervicales ont été fendues transversalement pour séparer la tête du reste du corps.

\subsubsection{Conditions d'élevage et d'abattage.}

C'est en particulier l'étude des fragments dentaires (mandibules, maxillaires et dents isolées) qui nous a permis d'évaluer l'âge et la composition des troupeaux élevés pour la consommation des habitants du Rocher des Vierges.

Malgré la quantié assez importante de mandibules et de maxillaires possédant des dents en place, nous n'avons pu qu'établir une classification de l'âge des bêtes basée sur des fourchettes chronologiques dont voici le détail :

Porc: $\mathrm{A}=$ de 8 jours à 5 mois

$\mathrm{B}=$ de 5 mois à 20 mois

$C=20$ mois et plus.

Mouton : $A=$ de 0 à 3 mois

$\mathrm{B}=$ de 3 mois à 10 mois

$\mathrm{C}=$ de 10 mois à 18 mois

$\mathrm{D}=18$ mois et plus.

A partir de là, nous avons obtenu les résultats suivants, toujours pour les couches 1001 et 1003. Quand cela était possible, nous avons précisé le sexe des animaux.

1001 :

Porc: $A$ : 7 indiv. $(1 \mathrm{~m})$ soit $30 \%$

B : 13 indiv. $(2 \mathrm{~m}, 3 \mathrm{f})$ soit $46 \%$

$C: 4$ indiv. (1 f) soit $24 \%$

Mouton : A : 28 indiv. soit $90,7 \%$

B : 1 indiv. soit $3,1 \%$

C: 1 indiv. soit $3,1 \%$

D : 1 indiv. soit $3,1 \%$

1003 :

Porc : A : 9 indiv. soit $26,5 \%$

B : 16 indiv. soit $47 \%$

C : 9 indiv. soit $26,5 \%$

Mouton : A : 20 indiv. soit $62,5 \%$

$$
\begin{aligned}
& \text { B : } 9 \text { indiv. soit } 28,1 \% \\
& \text { C: } 0 \text { indiv. } \\
& \text { D : } 3 \text { indiv. soit } 9,4 \%
\end{aligned}
$$

Ces résultats ont permis d'établir les deux diagrammes correspondant aux deux espèces (fig. 27 et 28 ).

\section{Porc.}

Les deux courbes sont très proches et atteignent sensiblement le même sommet. Ceci montre que la moitié du troupeau était abattue entre 5 et 20 mois et le tiers entre 8 jours et 5 mois (cochons de lait).

Toutefois, le reste des bêtes devait être gardé plus longtemps, certainement pour la reproduction et était consomme en fin de période reproductive. En effet, certaines mandibules présentent un état d'usure très avancé et des traces d'altération telles que formation de tartre, affections gingivales et abcès.

D'autre part, l'examen des fragments crâniens tels que l'os frontal et les maxillaires complets nous permettent d'identifier des porcs appartenant à la race sub-concave (d'après Jourdan, 1976).

\section{Mouton.}

Pour le mouton, les deux courbes présentent le même type de progression, si ce n'est que pour la couche 1003, il y a une totale absence d'individus dans la tranche $C$ (de 10 à 18 mois). Ceci indiquerait que les bêtes étaient abattues soit très jeunes, entre 0 et 3 mois pour la grande majorité, soit déjà âgées. Certaines mandibules et maxillaires présentent en effet un état d'usure suffisamment avancé pour nous laisser supposer que 
$\%$

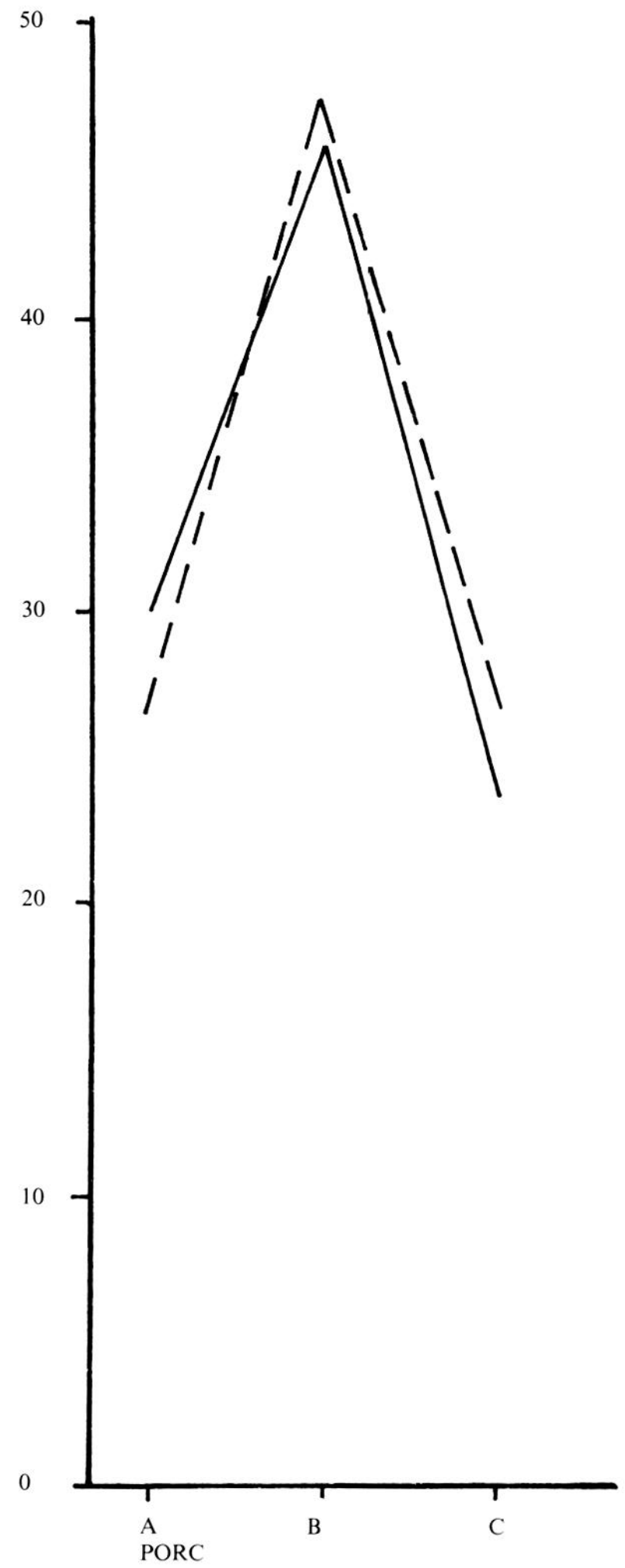

Fig. 27 : Courbe de répartition des porcs en fonction des tranches d’âge déterminées.

certains animaux étaient gardés longtemps, certainement à des fins reproductives.

\section{Beuf.}

Si le bœuf n'apparaît pas dans les diagrammes, c'est qu'i] est trop peu représenté et que les estimations d'âges sont moins sûres du fait du manque de matériel significatif. On peut toutefois signaler en 1001 un individu de moins de 40 mois et deux

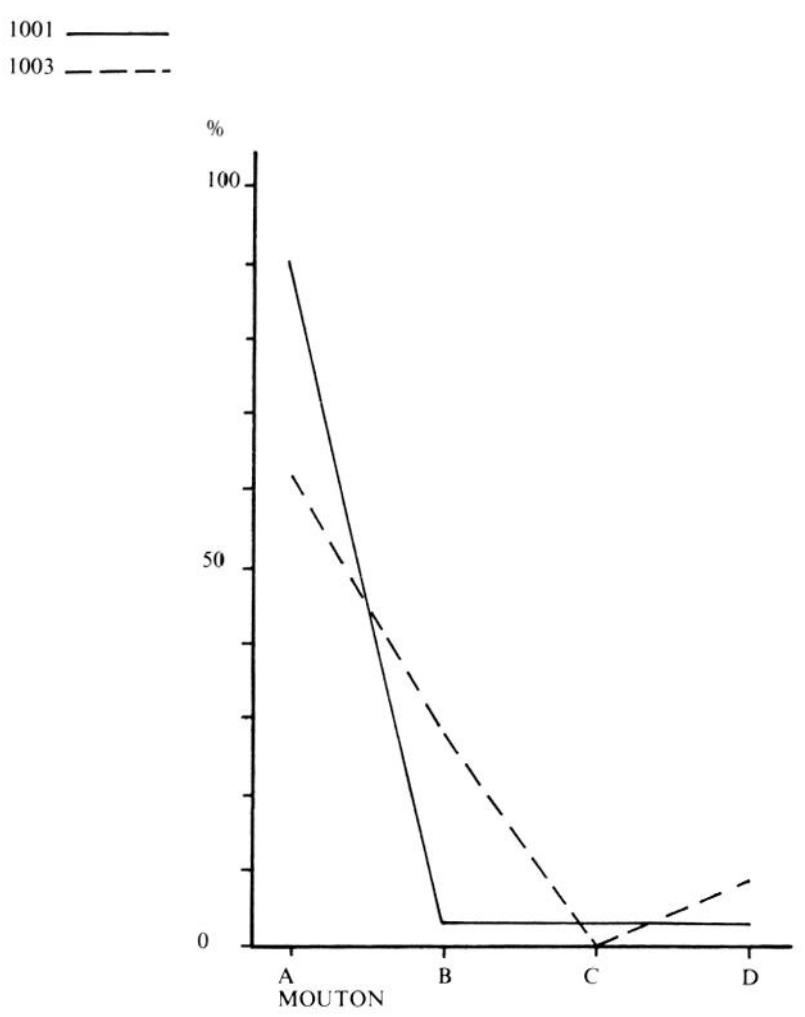

Fig. 28: Courbe de répartition des moutons en fonction des tranches d'âge déterminées.

de plus de 40 mois (dont un de plus de 48 mois). En 1003, nous avons un bœuf de 30 mois environ, un de plus de 30-34 mois et un de 40 à 50 mois ou plus.

\subsubsection{Conclusion.}

Malgré le caractère incomplet de ces résultats, il semble que nous puissions en tirer des informations révélatrices des tendances de l'alimentation.

Ainsi, les restes osseux jetés dans le dépotoir nous permettent de mieux cerner le mode de vie des occupants du Rocher des Vierges.

La première constatation serait que seuls des animaux domestiques sont représentés : bœuf, porc, mouton, chèvre (?), mais aussi oiseaux de basse-cour (poulet, canard, pintade, etc.).

La présence de lagomorphe est trop négligeable pour que l'on puisse parler de chasse au lièvre.

La mandibule de chat ne présentant pas le même état de conservation, nous ne pourrions affirmer qu'il s'agit là d'un chat de l'époque médiévale. Quant à la présence des coprolithiques de chien, et ce malgré l'absence d'ossements, elle confirme l'hypothèse que les os ont été rognés et mangés après leur dépôt. D'autre part, de nombreuses pièces présentent des traces de rongeurs et ceci pour toutes les couches.

En fait, les seuls animaux ne provenant pas d'un élevage sont les poissons dont les restes sont trop peu nombreux et pas assez significatifs pour permettre une détermination sûre.

Le fait de l'élevage des animaux consommés n'est malheureusement pas attesté par d'autres restes que les ossements : pas de traces de palissade, de poulailler ou d'étable, pas de matériel annexe relatif à l'élevage.

Les remarques occasionnées par les ossements euxmêmes ainsi que les proportions d'animaux, leur persistance et leurs âges nous ont permis d'en arriver à cette conclusion. La grande quantité d'ossements de très jeunes animaux de même que la présence de vieilles bêtes nous confirme dans l'idée que les bêtes étaient élevées sur place.

Un vieux mouton présentait un état d'usure et 
d'évolution anormale d'une dent supérieure dû à la perte d'une dent inférieure.

Nous citerons encore, d'un point de vue pathologique, outre les problèmes de caries, d'abcès ou de dents cassées, le cas d'un tibia de mouton présentant une importante exostose sur la diaphyse consécutive à une fracture de la patte. La fracture s'est ainsi réduite d'ellemême mais le mouton a dû boiter jusqu'à sa mort car les deux fragments du tibia se sont ressoudés tel quel c'est-à-dire, l'un contre l'autre et l'animal s'en est vu la patte racourcie d'autant. Chose qui ne se serait pas produite si on lui avait fixé une attelle le temps que l'os se soude. Ceci laisse supposer que les animaux devaient être livrés à eux-mêmes et étaient laissés en relative liberté aux alentours de l'habitat (66).

\section{Les aperçus sur la vie quotidienne.}

En ce qui concerne ce que l'on pourrait appeler les éléments de la vie quotidienne, le sondage effectué dans les soubassements de la tour apporte une somme de renseignements ponctuels dont certains concrétisent les données éparses de la documentation écrite.

Notre attention reste avant tout retenue par la présence d'un dépotoir important associant déchets inorganiques et déchet organiques, largement majoritaires, à l'intérieur même d'un bâtiment. Les renseignements stratigraphiques fournis par le sondage ne permettent pas de préciser si le dépotoir est contemporain de l'occupation de la tour ou de son abandon. Toujours est-il qu'aucune couche de destruction n'a été observée. Si la logique appuie la seconde hypothèse, certaines observations régionales n'excluent en rien la première.

Cette constatation qui ne peut être généralisée à l'ensemble du site traduit malgré tout une perspective d'insalubrité et de saleté de l'habitat. Ajoutons à cela que rongeurs et chiens devaient trouver dans ce tas de détritus une source quotidienne d'alimentation, comme l'a révélée l'étude ostéologique.

Une telle perspective loin d'apparaître comme un phénomène marginal lié strictement au Rocher des Vierges trouve des équivalences régionales mais aussi plus éloignées.

A Villejoubert, sur le site du castrum d'Andone, occupé au $\mathrm{X}^{\mathrm{e}}$ siècle, les fouilles ont révélé la présence « de nombreux tas de détritus en divers endroits et jus- que dans les bâtiments » (67).

Localement, les comparaisons sont nombreuses et réalisées sur des types d'habitats relativement identiques et vraisemblablement contemporains.

A Colombières-sur-Orb, le site de Saucani présente un bâtiment sommital révélant en surface une terre cendreuse où se mêlent de nombreux ossements (68).

Le château d'Olargues le Vieux, commune de Saint-Julien-d'Olargues, constitué d'un petit ensemble de salles rectangulaires massées au sommet d'un pic rocheux autorise pour la salle principale le même type d'observation (69).

Est-on en droit de rapprocher cette réalité archéologique de quelques descriptions littéraires publiées par Pierre Bonnassie (70) où la salle basse des tours, au niveau du sol, est appréhendée dans un vocabulaire effroyable : «dans les hideuses profondeurs de la tour »in tetra turris profunditas -.

L'analyse globale des documents constitués par les déchets du dépotoir s'est voulue exhaustive (71).

L'étude des céramiques, avant tout typologique, doit être maintenant complétée par quelques rapides constatations. L'exclusivité des formes fermées constituée par des vases à liquide, à cuire ou à conserver, doit être relativisée par l'existence d'une vaisselle en bois. Existence maintenant mieux perçue depuis les fouilles du village immergé de Colletières à Charavine (72). Dans ce cas précis, au $\mathrm{XI}^{\mathrm{e}}$ siècle, les objets en bois représentent plus de $60 \%$ du mobilier recueilli. Les formes ouvertes, liées à la consommation alimentaire et au service de la table sont alors fréquentes. Le même type d'information est révélé sur le site de Haus Meer, proche de Buderish pour les $\mathrm{XI}^{\mathrm{e}}-\mathrm{XII}^{\mathrm{e}}$ siècles (73). Par ailleurs, quelques documents font état de débats qui s'engagent à partir du $\mathrm{IX}^{\mathrm{e}}$ siècle à propos des matériaux pouvant être utilisés pour fabriquer les vases liturgiques (74). Ces textes concernent avant tout le monde religieux mais sont à même de révéler l'usage du bois dans la civilisation matérielle quotidienne.

Dans cet ordre d'idée, l'étude des restes osseux fournit une première impression sur l'alimentation carnée des habitants de la bordure montagneuse du bas pays languedocien, aux $\mathrm{X}^{\mathrm{e}}-\mathrm{XI}^{\mathrm{e}}$ siècles. Ces résultats qui attestent la prédominance très nette de l'élevage dans la consommation des produits animaux viennent utile-

(66) Bibliographie utilisée pour la rédaction de ce chapitre :

R. Barone, Anatomie comparée des mammifères domestiques, Vigot Frères, tome 1 Ostéologie, 1976.

J. Blanchard, Caractères permettant souvent de distinguer les canines inférieures des sangliers de celles des porcs domestiques, $B$. Soc. Preh. Franf., n 49, 1952, pp. 328-330.

$\mathrm{C}$. Cornevin et $\mathrm{X}$. Lesbre, Traité de l'áge des animaux domestiques d'après les derts et les productions épidermiques, Paris, 1894.

G. Demians d'Archimbaud, Les fouilles de Rougiers, contribution à l'archéologie de l'habitat rural médiéval én pays méditerranéen, C.N.R.S., 1980.

L. Jourdan, Etude de la faune du site gallo-romain de la Bourse. Marseille : les suidés. D.E.A. dactylographié, Marseille, 1971.

L. Jourdan, La faune du site gallo-romain et paléochrétien de la Bourse (Marseille), Ed. C.N.R.S., Paris, 1976.

F. Poplin, Origine du porc, Colloque d'ethnoscience, séance du 24 novembre. le porc domestique : Ethnozootechnie, 16, 1976 , pp. 6-13.

T. Poulain, Leétude des ossements animaux et son apport à l'archéologie, Publ. du centre de rech. sur les techniques grécoromaines, Université de Dijon, 6, 1976.

(67) A. Debord, Les fouilles du castrum d'Andone, Aquitania, I, 1983, pp. 173-200.

(68) G. Bellan et L. Schneider, op. cit.

(69) Renseignements oraux Florence Journot. Archéologie du château médiéval dans les bassins de l'Orb et de la Lergue, thèse en cours sous la direction de X. Barral, l. Altet (Université de Rennes).

(70) P. Bonnassie. La description des forteresses dans le livre des miracles de Sainte-Foy de Conques, Mél. M. de Bouard, Droz, 1982, pp. 17-26.

(71) Outre l'étude ostéologique, l'analyse des charbons de bois a été confiée à A. Durand. Le résultat de ce travail pour des raisons de délais de publication n'a pu être présenté dans cet article.

(72) R. et M. Colardelle. L'habitat médiéval immergé de Colletières à Charavines (Isère). Premier bilan des fouilles, Archéologie Médiévale, 10, 1980, pp. 192-194.

(73) W. Jansen, Die fruhmittelalterliche Niederungsburg bei Haus Meer, Schriftenreihe des Kreises Grevenbroich, 8, p. 112-113.

(74) G. Fournier, Usages et techniques de la vie quotidienne : vaisselle de bois, silos, Mél. M. de Bouard, Droz, 1982, pp. 155-169. 
ment compléter les rares renseignements qu'offre la documentation écrite (75). Caractère plus spécifique, que seule l'archéologie peut révéler, ils offrent une illustration des modes de débitage préférentiels par espèces animales et ce pour une période qui souffre de l'absence de textes utilisables dans ce domaine. Encore très ponctuelles, ces données se devront d'être étayées par l'étude d'autres séries contemporaines et plus tardives découvertes à Cabrières.

Si les restes osseux provenant d'animaux sauvages sont inexistants, les nombreux fragments de trompes d'appel tendent à prouver cependant la pratique de la chasse, activitée précieuse pour le complément de viande, de peaux et de fourrures qu'elle peut fournir (76).

Enfin, la seule activité domestique prouvée par la fouille est le filage de la laine, avec les treize fusaïoles découvertes.

\section{Conclusion.}

L'étude du site du Rocher des Vierges a permis de cerner par une série de démarches complémentaires le contexte d'un castrum héraultais des environs de l'an Mil. Ces diverses disciplines alliées dans une même quête ont permis de lier l'histoire des structures du peuplement d'une micro-région à un exemple limité dans le temps et dans l'espace.

Aux alentours du $\mathrm{X}^{\mathrm{e}}$ siècle, un habitat s'installe isolé et perché à la limite de la plaine et des plateaux de l'arrière-pays. Les termes usités dans les textes, l'étude architecturale exhaustive assignent à cette implantation un caractère défensif et fortifié. La mention, au XI' siècle, d'une famille propriétaire ou gardienne du bâti affine la définition de l'ensemble.

Le castrum du Rocher des Vierges est un habitat aristocratique et militaire fondé avant tout sur le contrôle de voies de communication et demeuré au cours des siècles fidèle à sa vocation primitive. Volontairement ou non, il semble être resté un témoin des phénomènes ayant entraîné les mutations et les déplacements advenus dans la plaine, phénomènes pour lesquels il a toutefois servi de point de repère monumental.

Ce castrum est surtout la résidence d'un lignage noble. L'un n'a pas dans ce cas de raisons d'exister sans l'autre. Les murs semblent subir un abandon avec l'ex- tinction de la ligne directe des "des Deux Vierges », aux $\mathrm{XIV}^{e_{-}} \mathrm{XV}^{\mathrm{e}}$ siècles, ce par la faute de dirigeants n'ayant pas su ou voulu être attractifs et muer leur demeure en foyer de regroupement.

La concentration de l'habitat s'est effectuée en contrebas autour d'une ancienne église domaniale Saint-Saturnin-de-Lucian - (77), d'une façon indépendante vraisemblablement sans lien causal avec le castrum.

En définitive, le site du Rocher des Vierges offre un exemple encore très mal connu de ce que fut le castrum originel, c'est-à-dire une pièce centrale de la châtellenie.

Situé dans une zone de contact entre Massif Central et plaine languedocienne, il est à même de révéler l'aspect primitif de l'habitat per castra, celui du premier âge féodal. De par sa morphologie le castrum du Rocher des Vierges s'oppose nettement au castrum populatum des plaines aquitaines (78) et languedociennes (79) caractérisé par la richesse de son terroir, l'abondance de sa population et qui répond en fait à une évolution plus tardive, celle de la vague de concentration de l'habitat, mutation secondaire du phénomène castral.

La monographie ainsi établie pour le site de SaintSaturnin gagnerait à être complétée par une démarche identique effectuée sur le castrum originel de la basse plaine ayant systématiquement subi l'incastellamento. Elle permettrait sans doute de mieux cerner son état avant qu'il ne soit englobé dans un urbanisme naissant où l'habitat seigneurial - castrum primitif - voit son importance décliner au profit de l'enceinte collective.

Si le Rocher des Vierges n'apparaît pas comme un foyer de peuplement, il faudra tout de même préciser qu'il a du motiver l'installation de toute une domesticité aristocratique à ses abords immédiats. Cette domesticité est révélée partiellement par la fouille: nécessité d'un gardiennage pour les bêtes élevées, de bouchers pour la préparation des aliments carnés mais aussi pour des activités plus spécifiques comme le filage de la laine.

Enfin, analyser les vestiges mobiliers et immobiliers d'une telle entreprise humaine, outre l'apport de précieux repères typo-chronologiques, est nécessaire si l'on veut éclairer dans le détail les caractères quotidiens d'une société jusqu'alors saisie dans ses lignes fondamentales.

(75) M. Gramain, Les formes de l'élevage en bas Languedoc occidental aux XIII et XIVc siècles, L'élevage en méditerranée occidentale, éd. du C.N.R.S., Marseille 1977, pp. 137-152 (Actes du colloque international de l'institut de recherches méditerranéennes, Sénanque, mai 1976).

(76) Aujourd'hui le Moyen Age, Cataloguc d'cxposition, Sćnanquc, 1981, pp. 105-108.

(77) Cf. chapitre 3-3.

(78) B. Cursente, Les castelnaux de la Gascogne médiévale. Gascogne gersoise, Bordeaux, 1980.

(79) M. Bourin, op. cit., D. Baudreu, Une forme de villages médiévaux concentrés : le cas du Bas-Razès, Archéologie du Midi Médiéval, 4, 1986, pp. 49-73. 